\title{
Arginine (Di)methylated Human Leukocyte Antigen Class I Peptides are Favorably Presented by HLA-B*07
}

Fabio Marinot, ${ }^{\dagger,}$ Geert P.M. Mommen ${ }^{\dagger, \downarrow \S}$, Anita Jekot, ${ }^{\dagger}$, Hugo D. Meiring§, Jacqueline A.M. van Gaans-van den Brink", Richard A. Scheltemat, , Cécile A.C.M. van Els" , Albert J. R. Heck ${ }^{\dagger, \neq * *}$

† Biomolecular Mass Spectrometry and Proteomics, Bijvoet Center for Biomolecular Res earch and Utrecht Institute for Pharmaceutical Sciences, Utrecht University, Padualaan 8, $3584 \mathrm{CH}$ Utrecht, The Netherlands.

¥ Netherlands Proteomics Centre, Padualaan 8,3584 CH Utrecht, The Netherlands.

$\S$ Institute for Translational Vaccinology, P.O. Box 450, 3720 AL Bilthoven, The Netherlands.

"Centre for Infectious Disease Control, National Institute for Public Health and the Envir onment, P.O. Box 1, 3720 AL Bilthoven, The Netherlands.

*E-mail:a.j.r.heck@uu.nl

\section{Abstract}

Alterations in protein post-translational modification (PTM) are recognized hallmarks of diseases. These modifications potentially provide a unique source of disease-related human leukocyte antigen (HLA) class I-presented peptides that can elicit specific immune responses. While phosphorylated HLA peptides have al ready received attention, arginine methylated HLA class I peptide presentation has not been characterized in detail. In a human B-cell line we detected 149 HLA class I peptides harboring monoand/or dimethylated arginine residues by mass spectrometry. A striking preference was observed in the presentation of arginine (di)methylated peptides for HLA-B*07 molecules, likely because the binding motifs of this allele resemble consensus sequences recognized by arginine methyl-transferases. Moreover, HLA-B*07-bound peptides preferentially harbored dimethylated groups at the $\mathrm{P} 3$ position, thus consecutively to the proline anchor residue. Such a proline-arginine sequence has been associated with the arginine methyl-transferases CARM1 and PRMT5. Making use of the specific neutral losses in fragmentation spectra, we found most of the peptides to be asymmetrically dimethylated, most likely by CARM1. These data expand our knowledge of the processing and presentation of arginine (di)methylated HLA class I peptides and demonstrate that these types of modified peptides can be presented for 
recognition by T-cells. HLA class I peptides with mono- and dimethylated arginine residues may therefore offer a novel target for immunotherapy. 


\section{Supplementary Tables}

Supplementary Table 1: List of identified (di)methylated unique peptides and their features, in each biological replicate and cumulatively for the two experiments. The table contains also a summary of the findings.

Supplementary Table 2: Comparison between monomethylated/unmodified, dimethylated/unmodified and dimethylated/monomethylated peptides identified and quantified in the same LC-MS/MS run.

\section{Supplementary Figures}

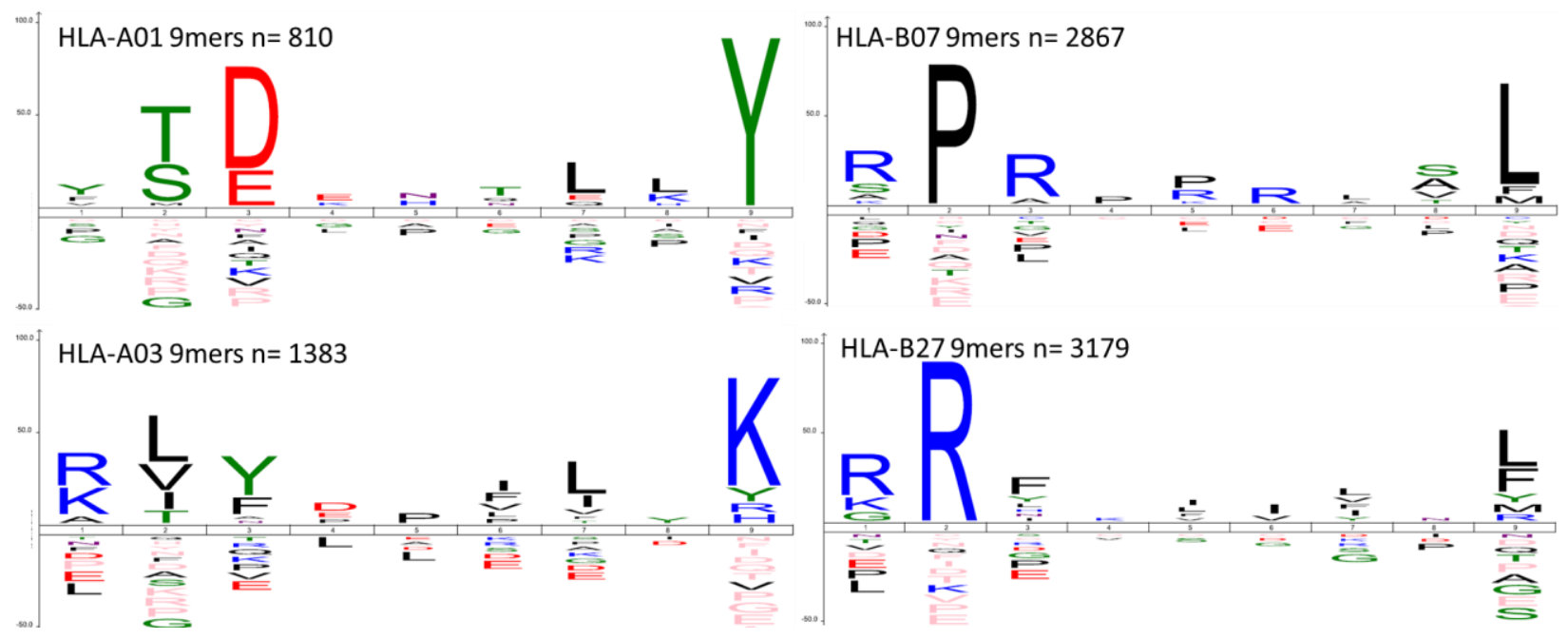

Supplementary Figure 1. It represents the sequence motifs of the identified unmodified HLA class I peptides. The NetMHC algorithm was used for binding affinity prediction and assignment of the set of identified (unmodified) peptides to HLA-A*01, $-A^{*} 03,-B^{*} 07$ and $-B^{*} 27$. Analysis was restricted to peptides 9 amino acids in length. 


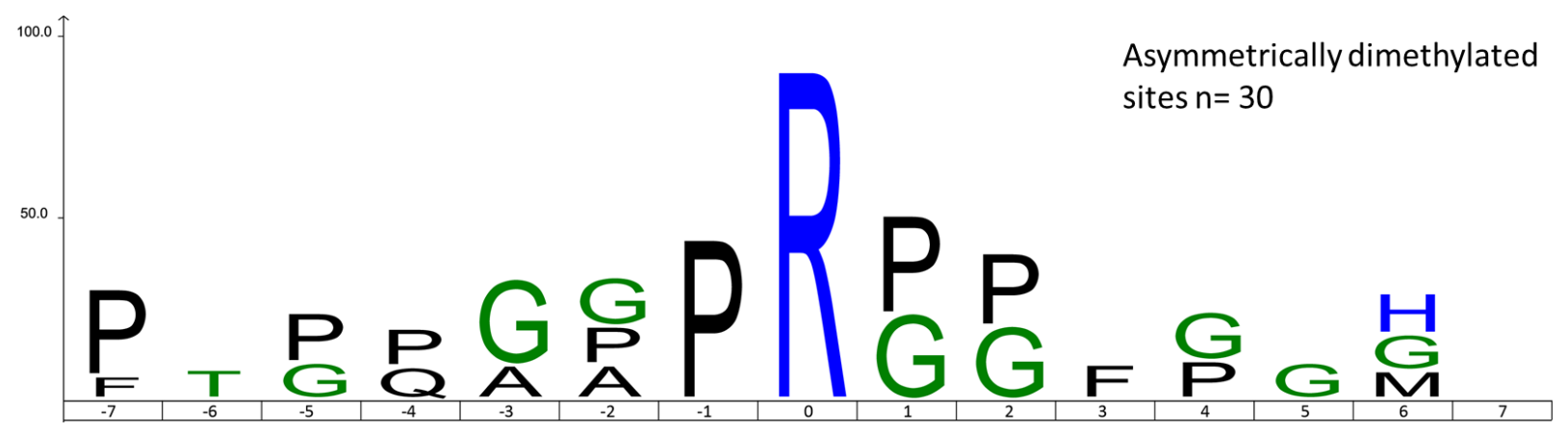

Supplementary Figure 2. The figure displays the sequence motif of asymmetrically dimethylated sites in the HLA ligandome. The sequence motif shows the preference of amino acid flanking the asymmetrically dimethylation (ADMA) sites identified on HLA class I peptides.

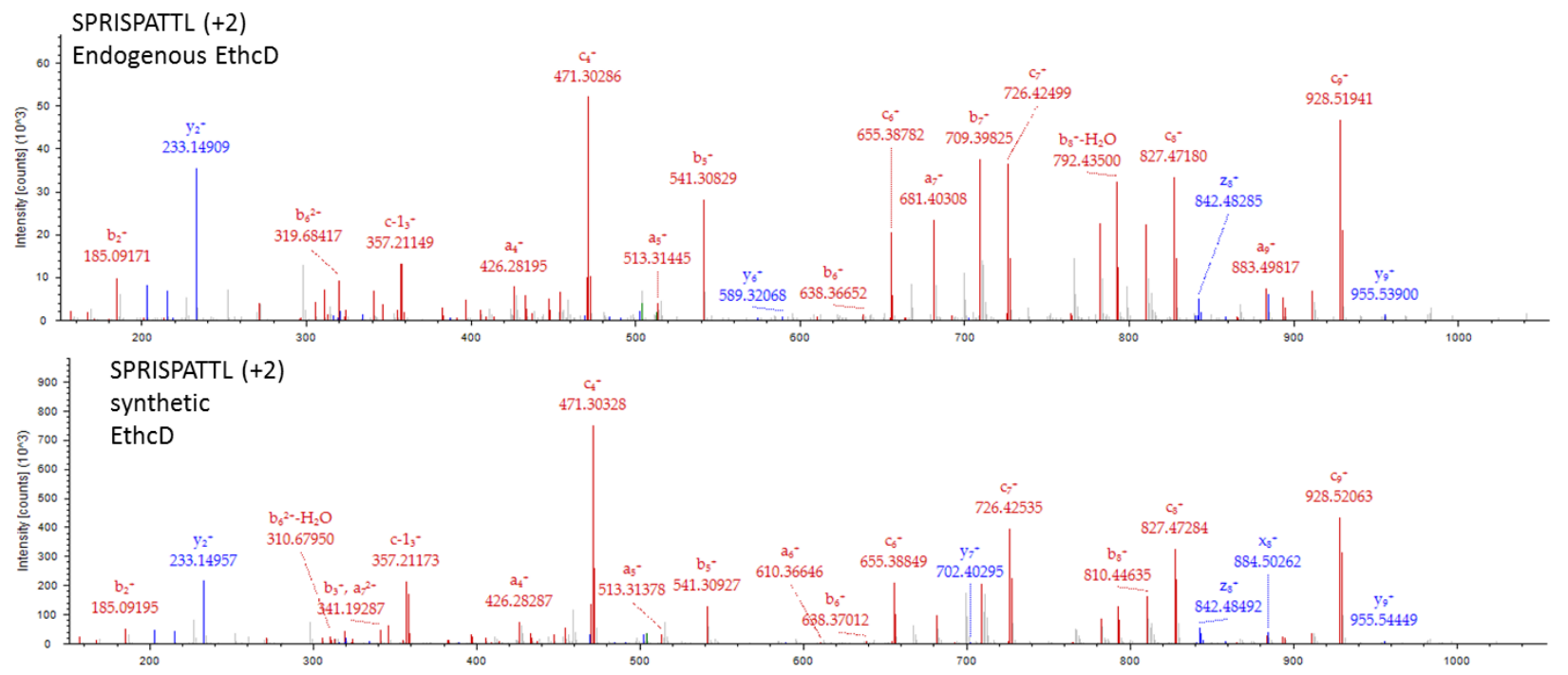

Supplementary Figure 3. EThcD spectra of the endogenous unmodified HLA class I peptide SPRISPATTL (top). For comparison the EThcD spectrum of the synthetic peptide analogue is given (bottom). This peptide originates from the AT-Rich Interactive Domain-Containing Protein 3B. 

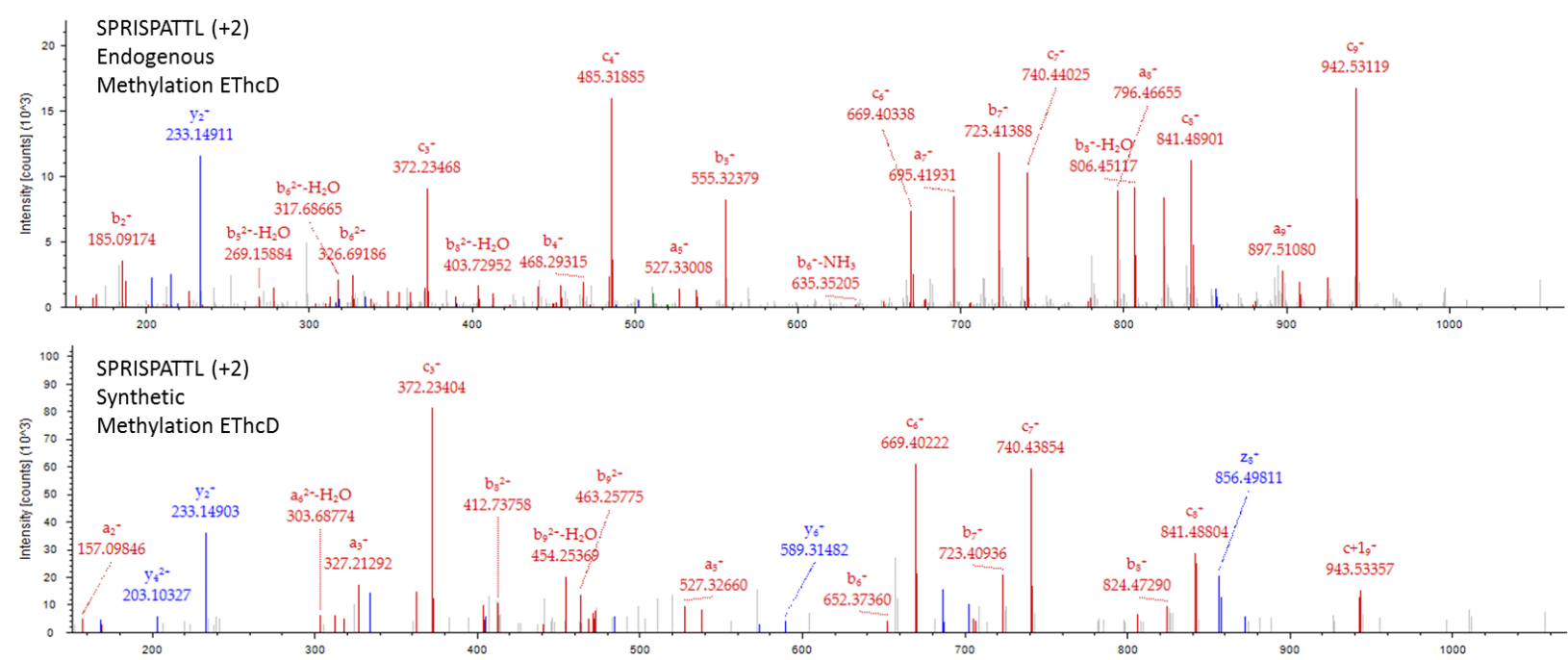

Supplementary Figure 4. EThcD spectra of the endogenous P3 monomethylated HLA class I peptide SPRISPATTL

(top). For comparison the EThcD spectra of the synthetic peptide analogue is given (bottom). The peptide originates from the protein AT-Rich Interactive Domain-Containing Protein 3B.

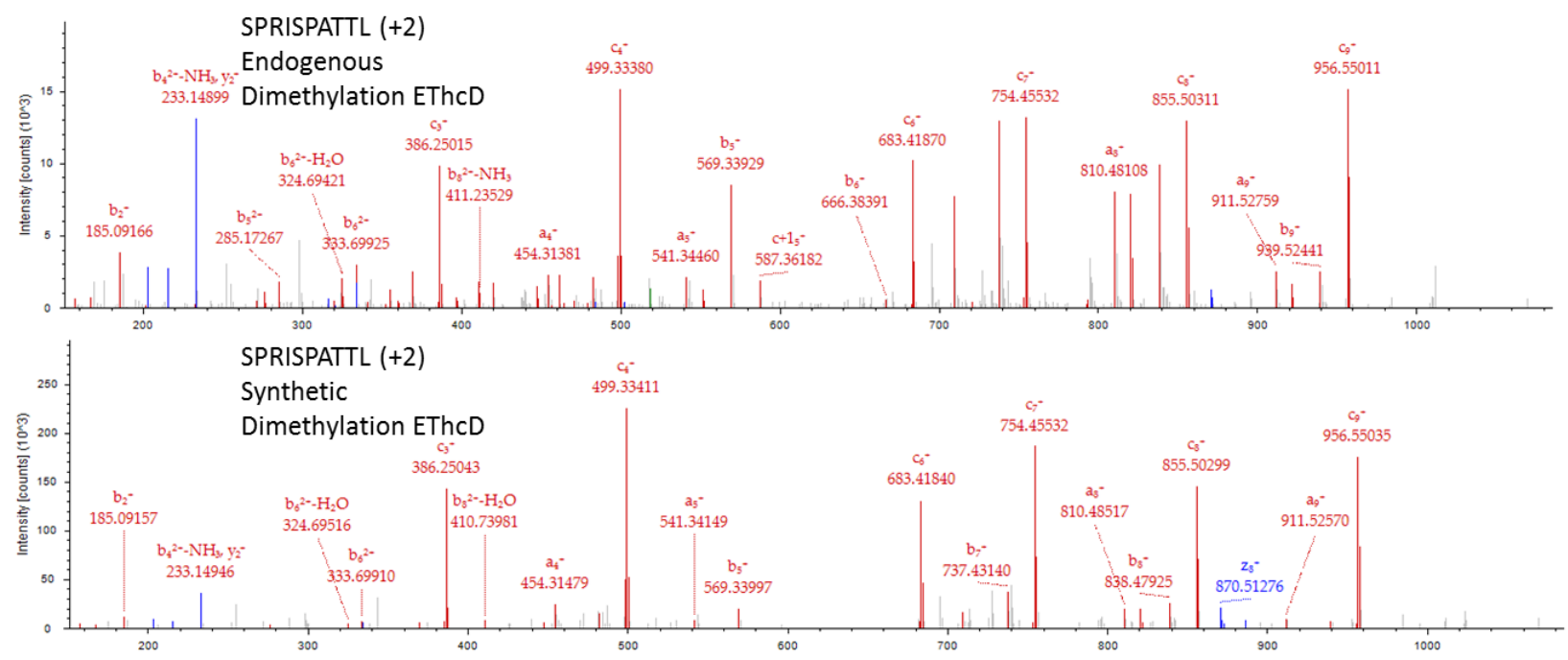

Supplementary Figure 5. EThcD spectra of the endogenous P3 dimethylated HLA class I peptide SPRISPATTL (top). For comparison the EThcD spectra of the synthetic peptide analogue is given (bottom). The peptide originates from the protein AT-Rich Interactive Domain-Containing Protein 3B. 


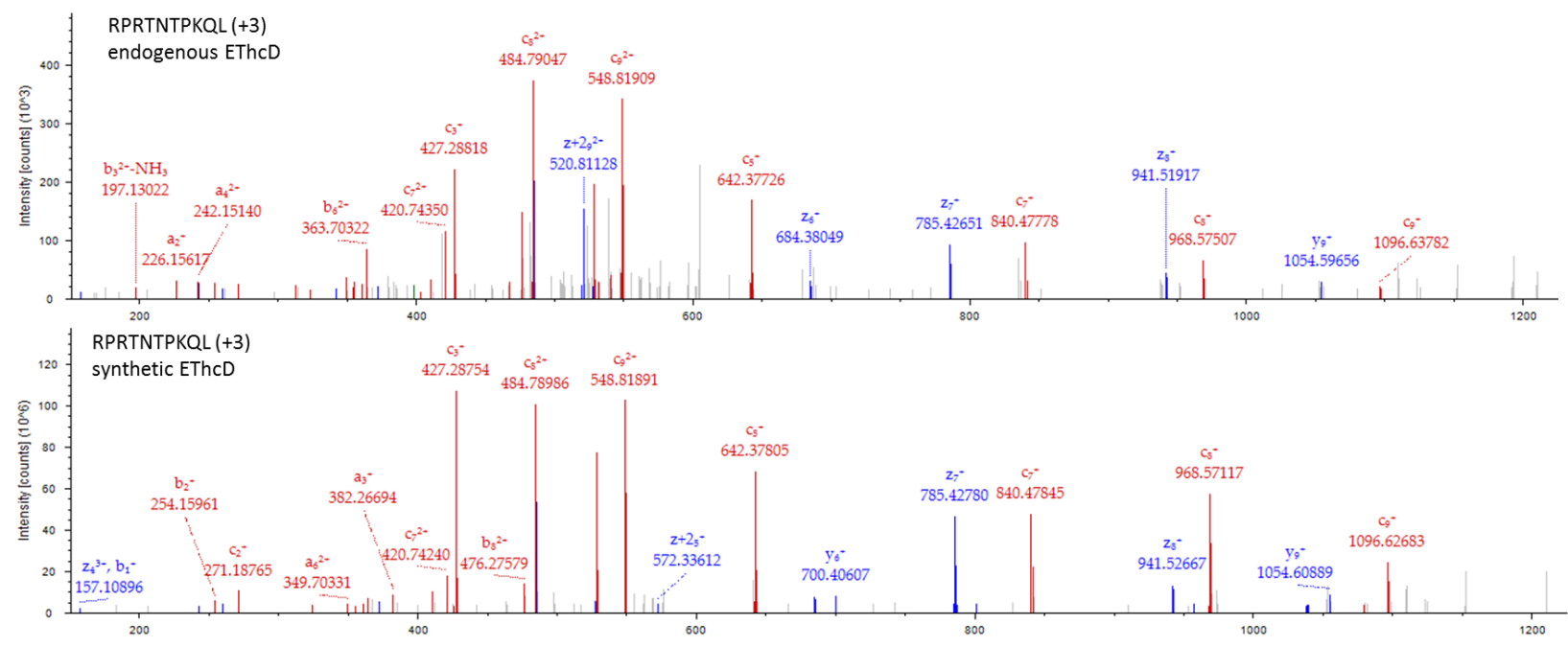

Supplementary Figure 6. EThcD spectra of the endogenous unmodified HLA class I peptide RPRTNTPKQL (top). For comparison the EThCD spectrum of the synthetic peptide analogue is given (bottom). This peptide originates from the protein Nuclear Receptor Coactivator 3.

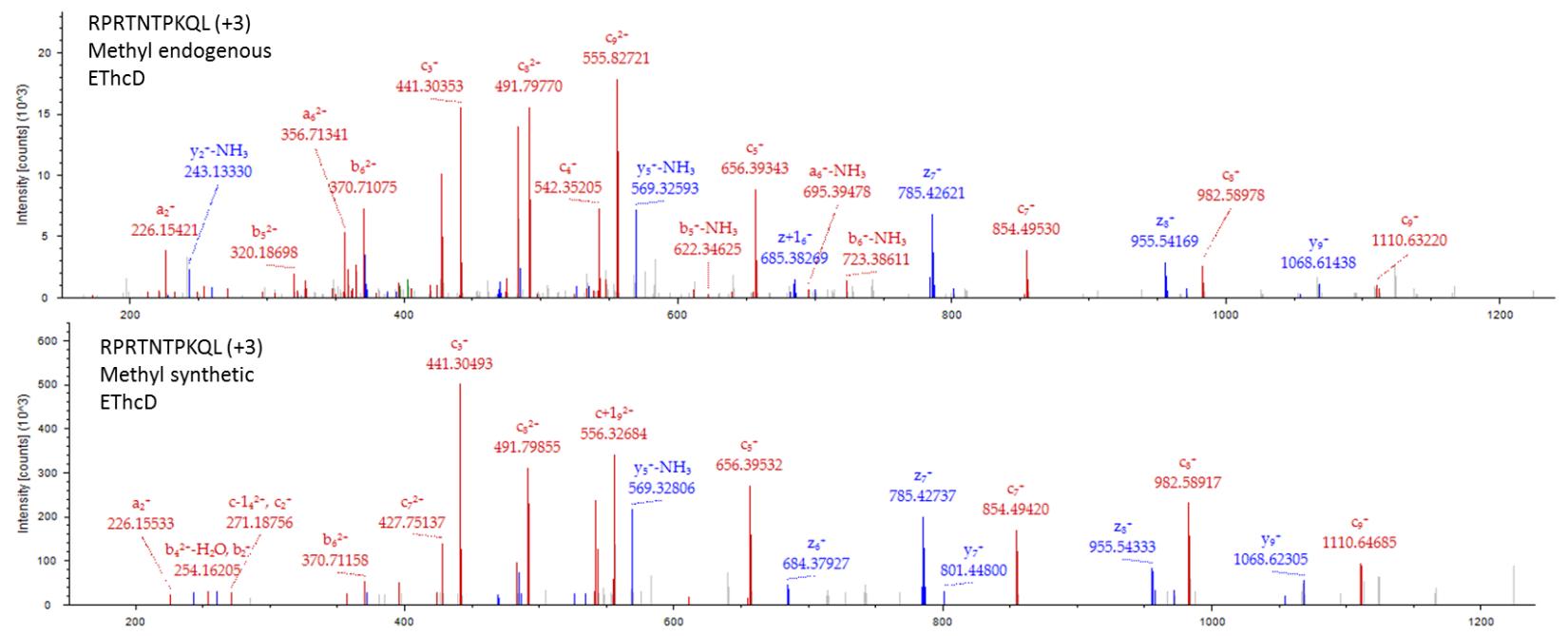

Supplementary Figure 7. EThcD spectra of the P3 monomethyl modified peptide RPRTNTPKQL HLA class I peptide RPRTNTPKQL (top). For comparison the EThcD spectrum of the synthetic peptide anal ogue is given (bottom). This peptide originates from the protein Nuclear Receptor Coactivator 3. 

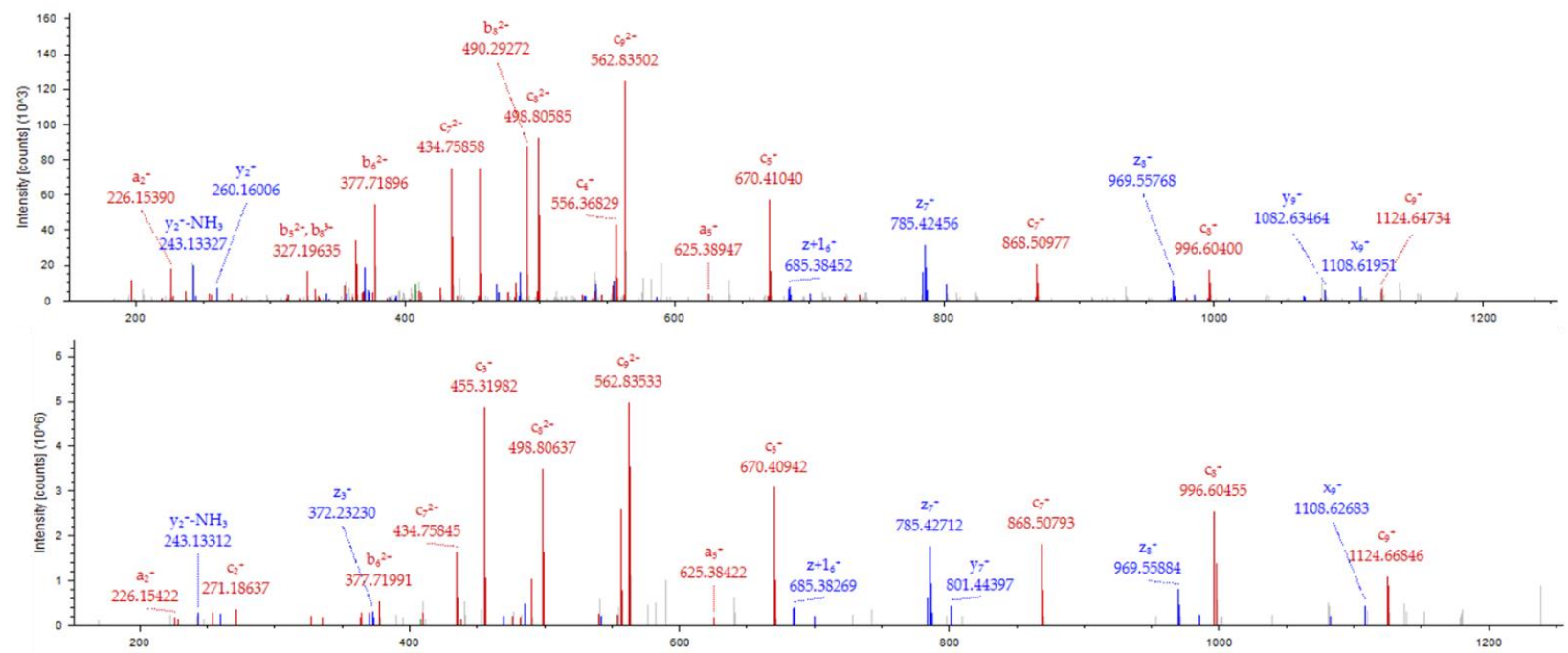

Supplementary Figure 8. EThCD spectra of the P3 dimethyl modified peptide RPRTNTPKQL HLA class I peptide RPRTNTPKQL (top). For comparison the EThcD spectrum of the synthetic peptide analogue is given (bottom). This peptide originates from the protein Nuclear Receptor Coactivator 3.
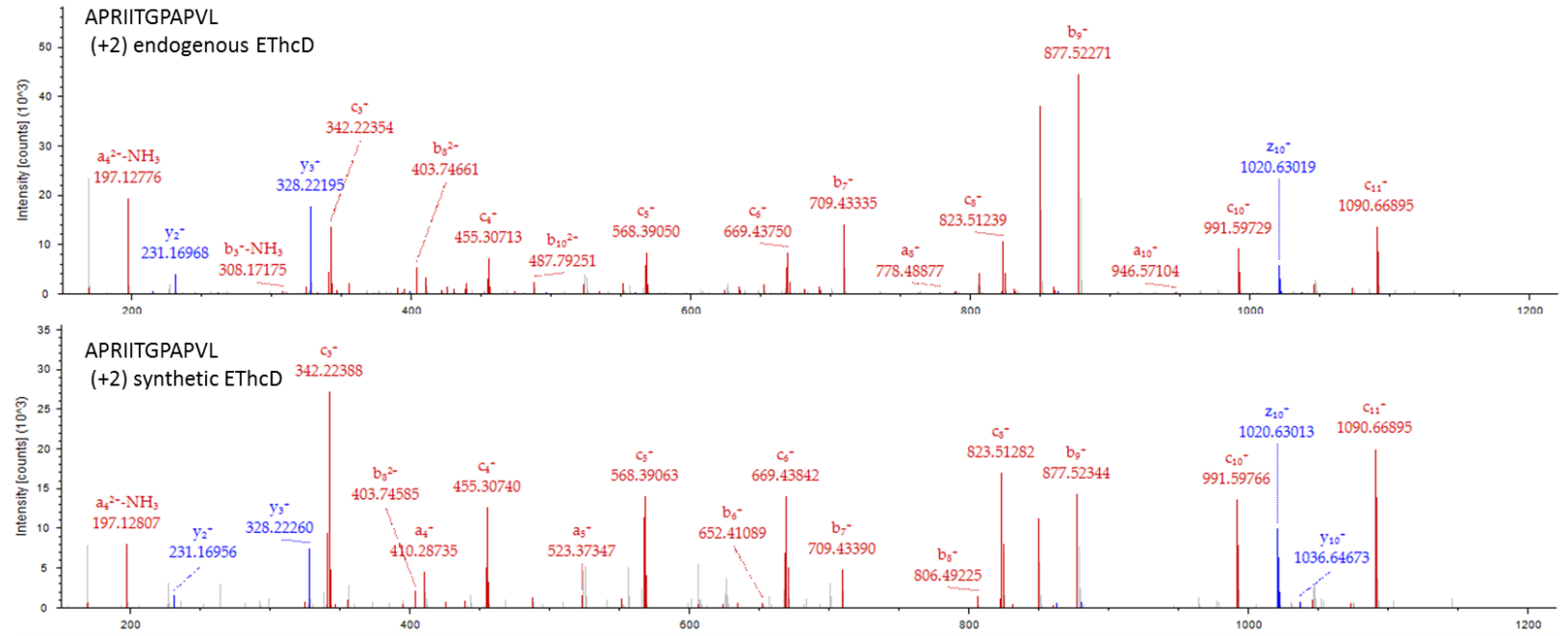
Supplementary Figure 9. EThcD spectra of the endogenous unmodified HLA class I peptide APRIITGPAPVL (top). For comparison the EThCD spectrum of the synthetic peptide analogue is given (bottom). This peptide originates from the protein of origin the protein Protein Quaking.

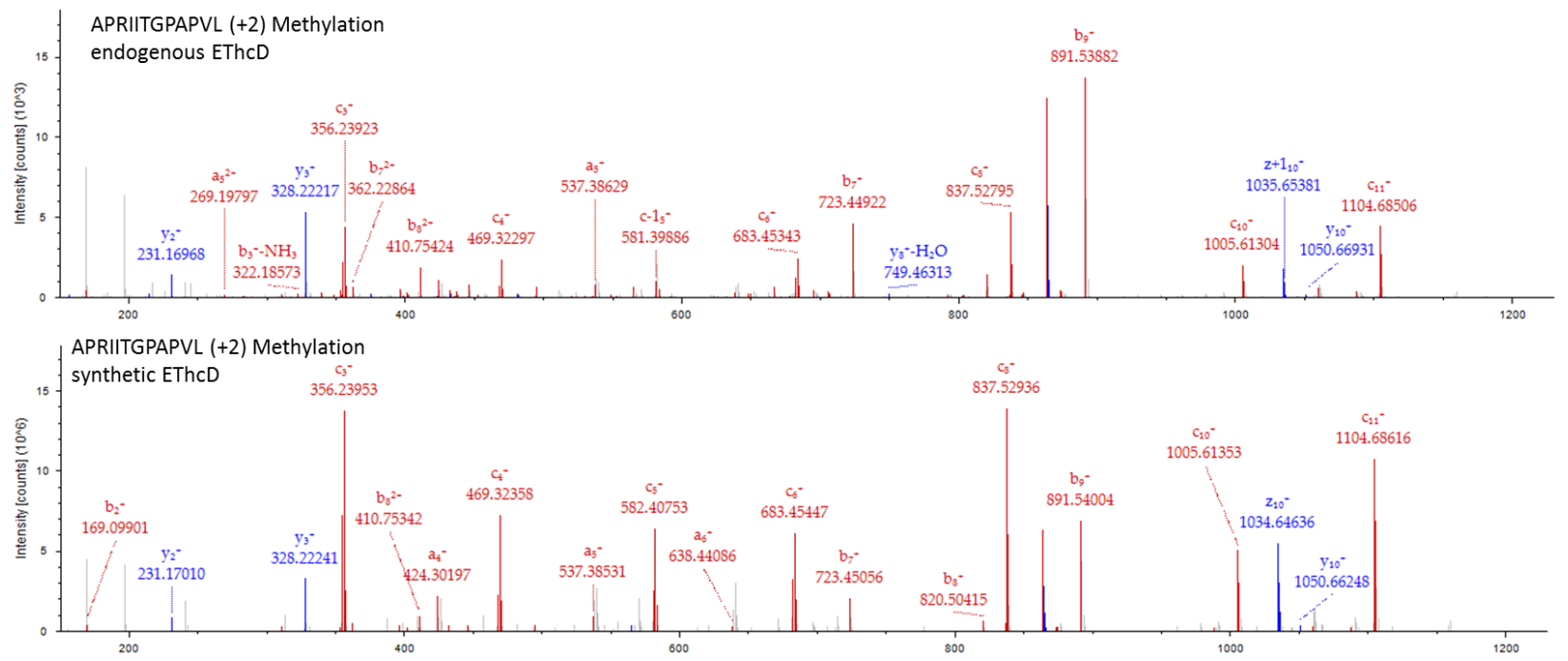

Supplementary Figure 10. EThcD spectra of the P3 monomethyl modified peptide APRIITGPAPVL HLA class I peptide (top). For comparison the EThcD spectrum of the synthetic peptide analogue is given (bottom). This peptide originates from the protein Protein Quaking. 

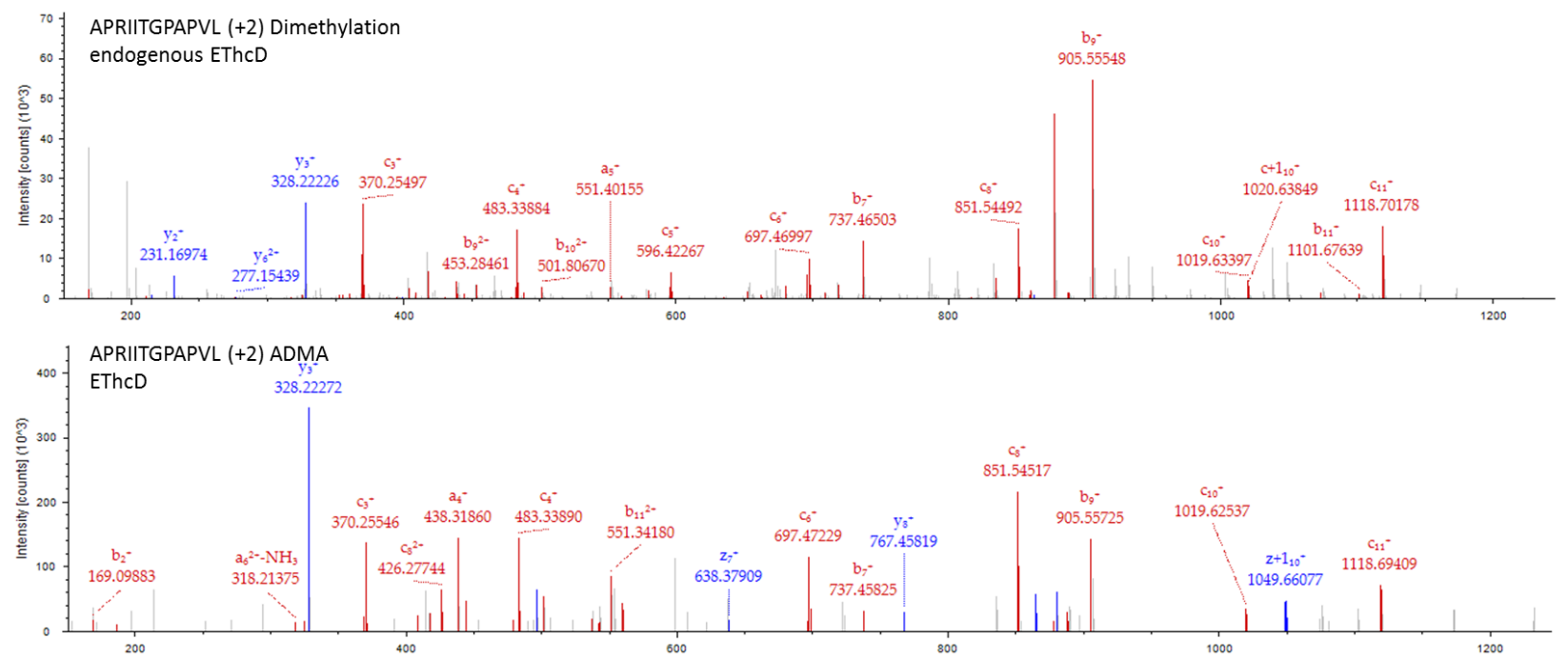

Supplementary Figure 11. EThcD spectra of the P3 dimethyl modified peptide APRIITGPAPVL HLA class I peptide (top). For comparison the EThcD spectrum of the synthetic peptide analogue is given (bottom). This peptide originates from the protein Protein Quaking.

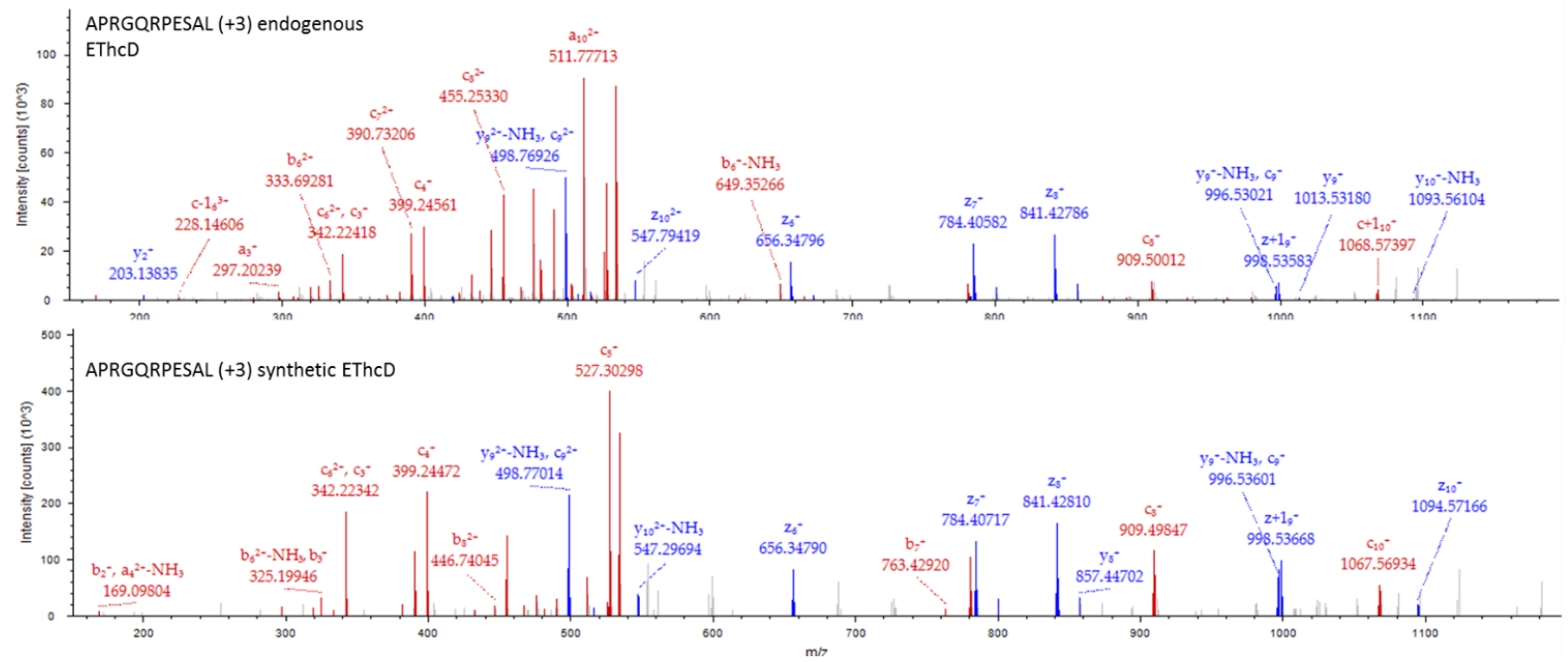

Supplementary Figure 12. EThcD spectra of the endogenous unmodified HLA class I peptide APRGQRPESAL (top). For comparison the EThcD spectrum of the synthetic peptide analogue is given (bottom). This peptide originates from the protein of origin the protein Proteasome Subunit Beta Type-8. 

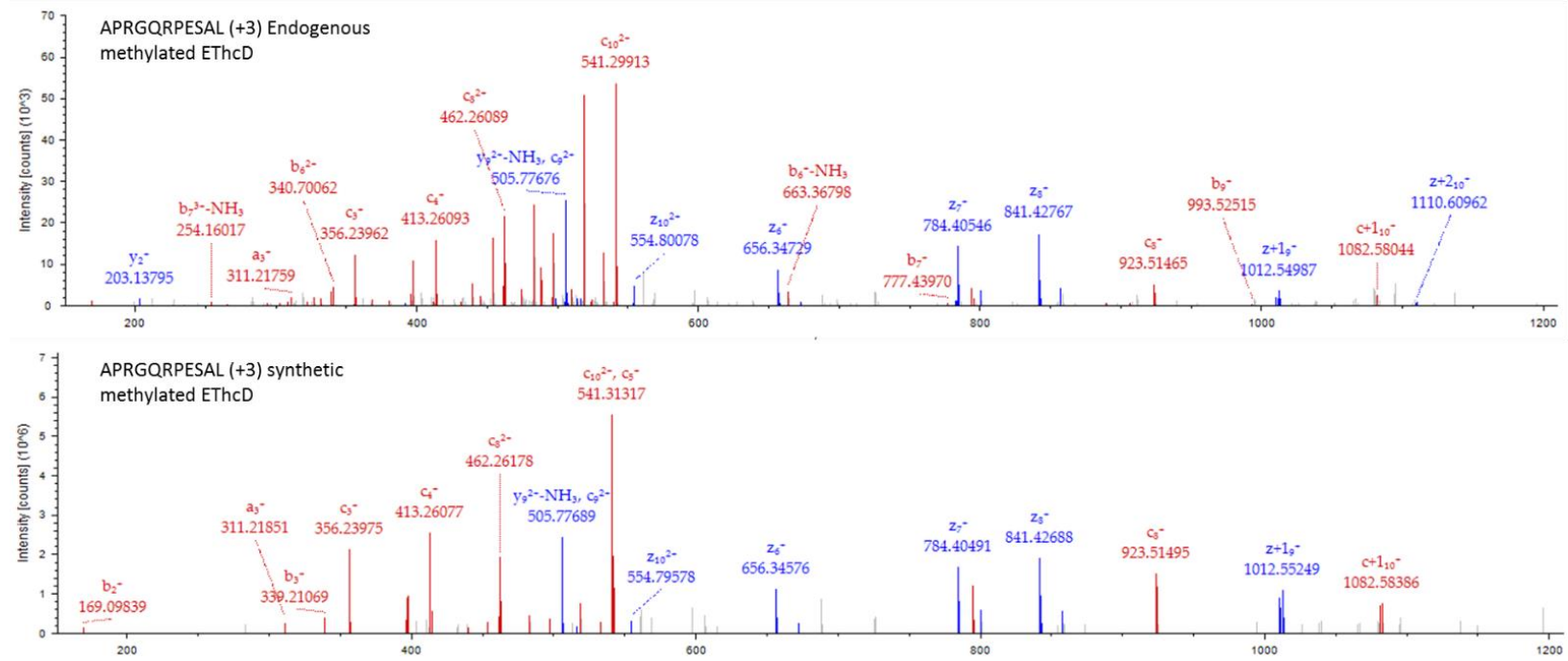

Supplementary Figure 13. EThcD spectra of the P3 monomethyl modified peptide APRGQRPESAL HLA class I peptide (top). For comparison the EThcD spectrum of the synthetic peptide analogue is given (bottom). This peptide originates from the protein Proteasome Subunit Beta Type-8.

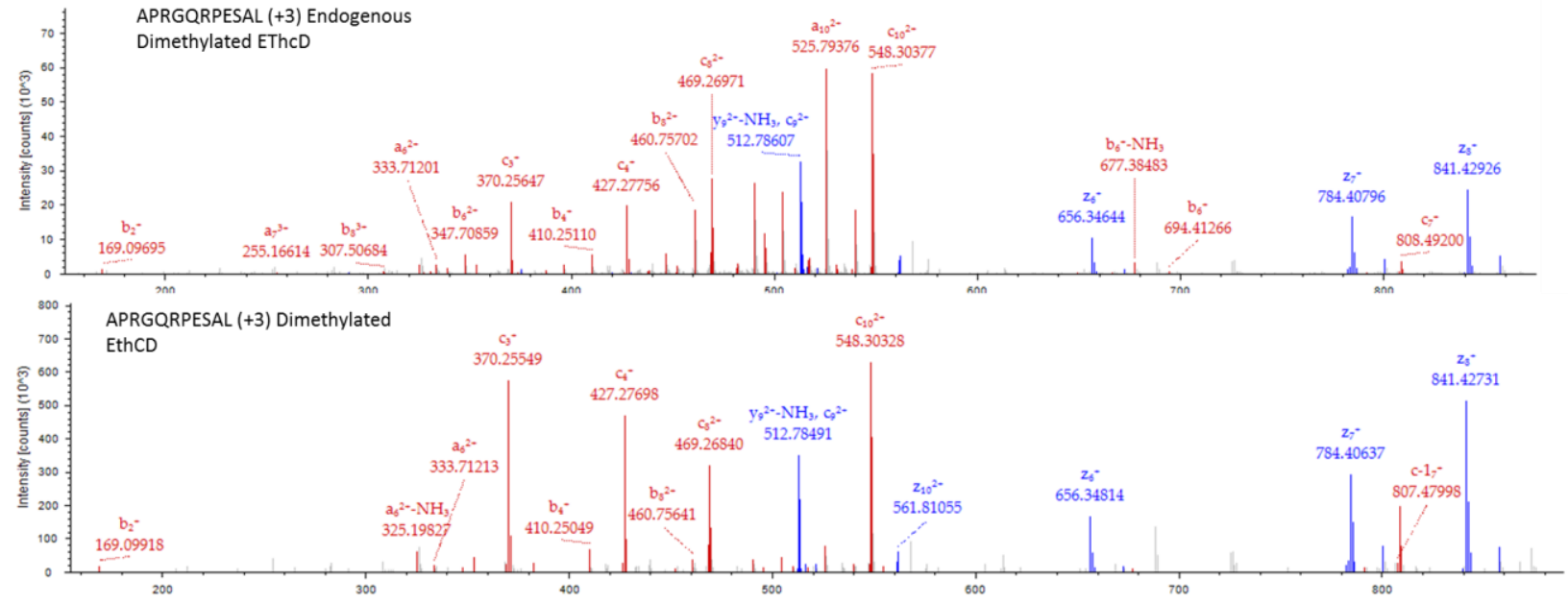

Supplementary Figure 14. EThCD spectra of the P3 dimethyl modified peptide APRGQRPESAL HLA class I peptide (top). For comparison the EThcD spectrum of the synthetic peptide analogue is given (bottom). This peptide originates from the protein Proteasome Subunit Beta Type-8. 


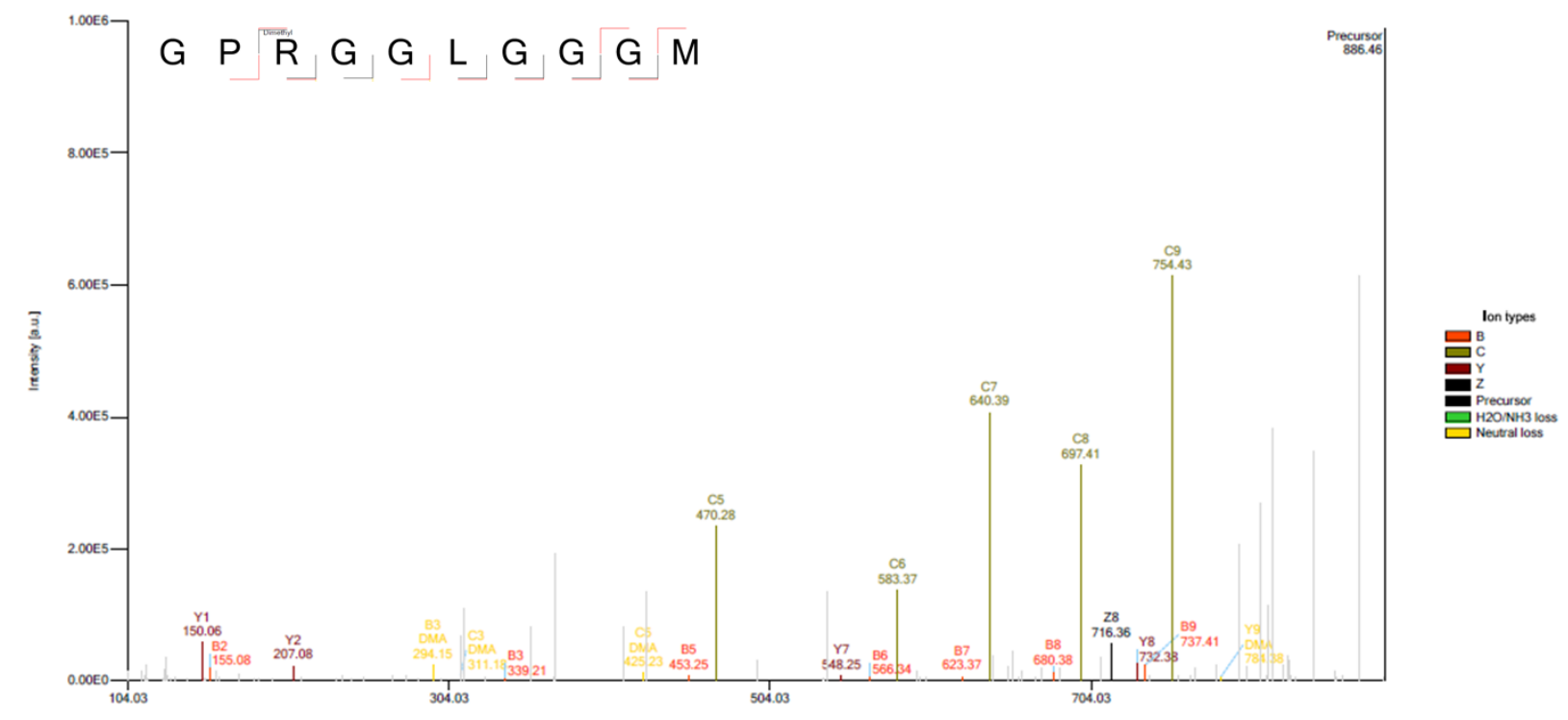

Supplementary Figure 15. EThCD spectra of the P3 asymmetrycally dimethyl (ADMA) modified peptide GPRGGLGGM from the protein of origin Ras GTPase-activating protein-binding protein 1 (G3BP-1). The neutral losses specific for asymmetrical dimethylation are pointed in yellow in the spectra. The peptide was predicted as a HLA-B*07 binder.

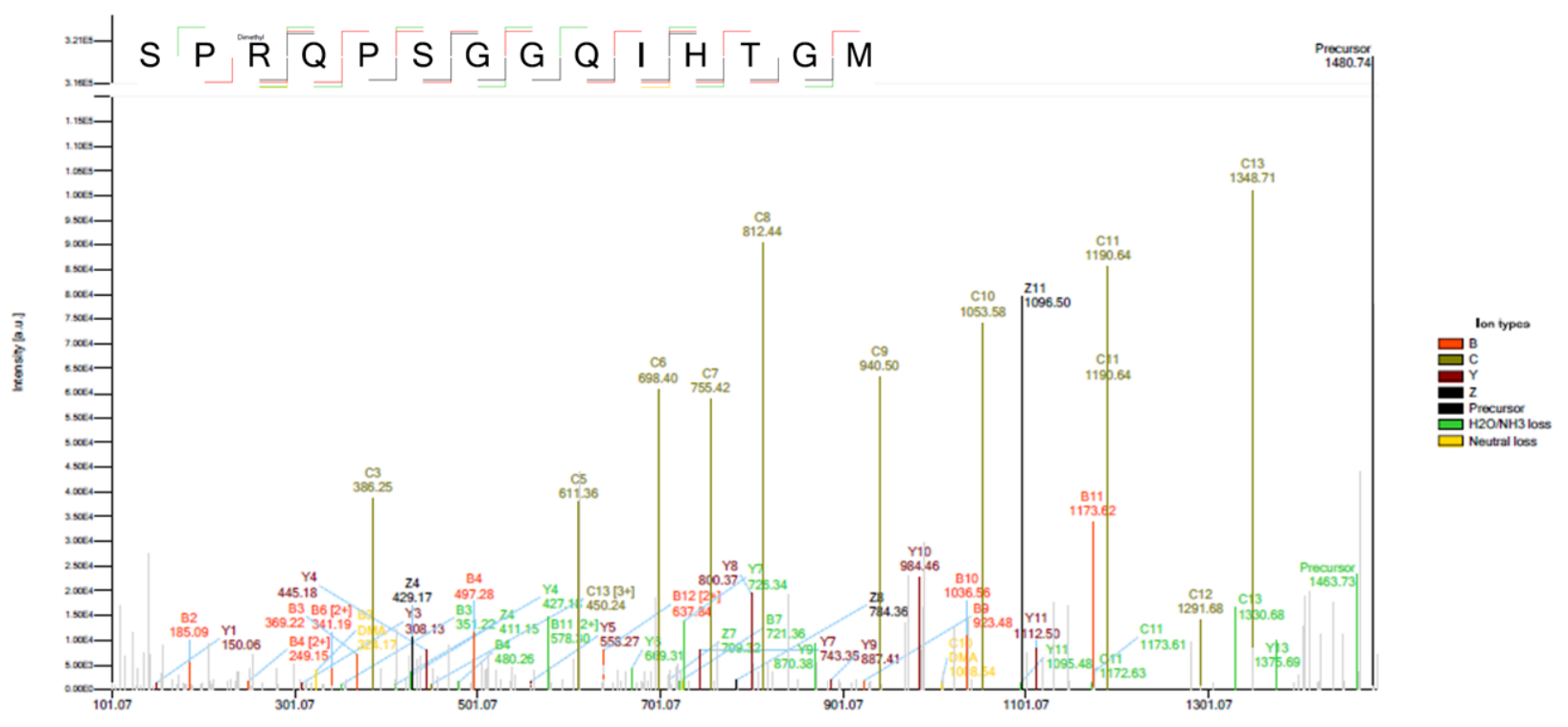


Supplementary Figure 16. EThcD spectra of the P3 asymmetrycally dimethyl (ADMA) modified peptide SPRQPSGGQIHTGM from the protein of origin AT-rich interactive domain-containing protein 1A (ARID domaincontaining protein $1 \mathrm{~A})$. The neutral losses specific for asymmetrical dimethylation are pointed in yellow in the spectra. The peptide was predicted as a HLA-B*07 binder.

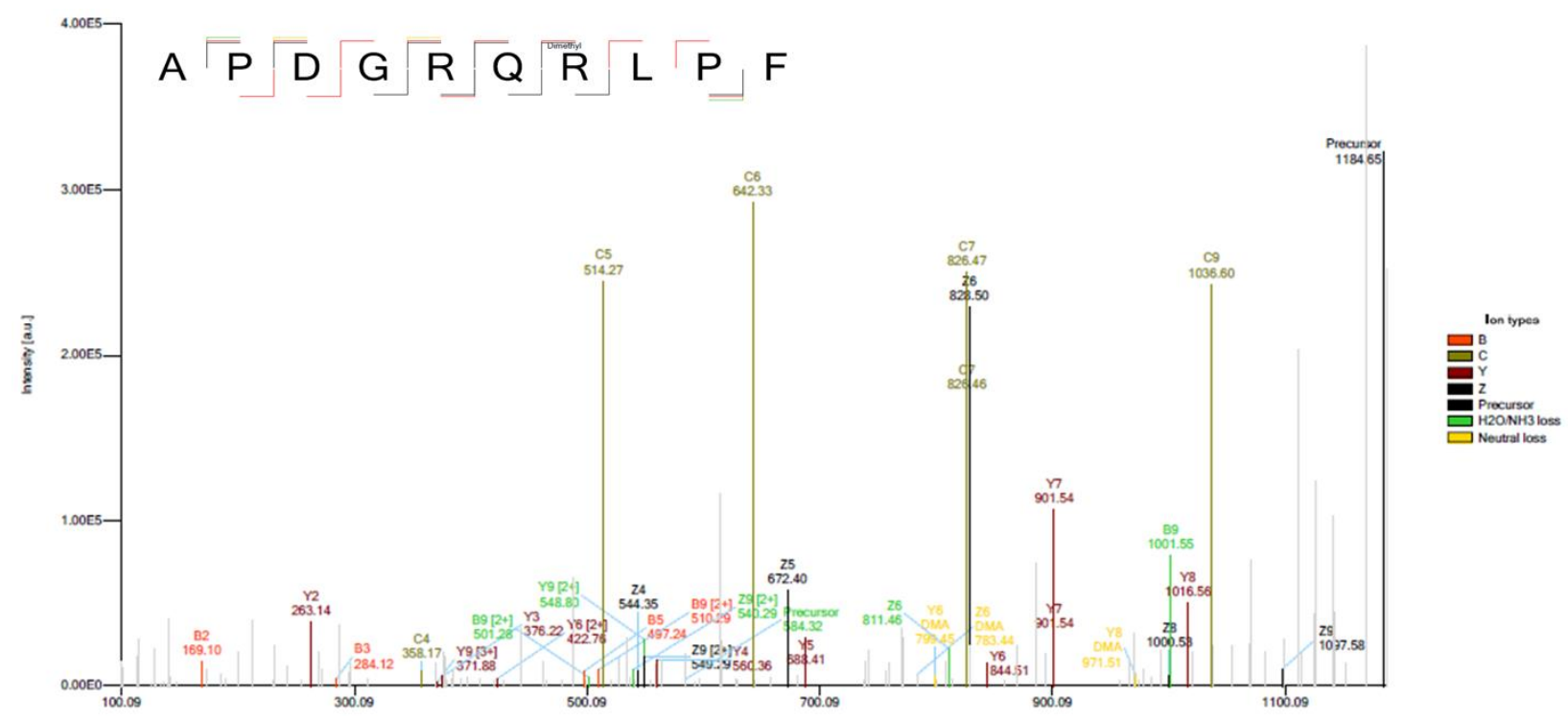

Supplementary Figure 17. EThcD spectra of the P6 asymmetrycally dimethyl (ADMA) modified peptide APDGRQRLPF from the protein of origin Histone-lysine N-methyltransferase 2C (Lysine N-methyltransferase 2C). The neutral losses specificfor asymmetrical dimethylation are pointed in yellow in the spectra. The peptide was predicted as a HLA-B*07 binder. 


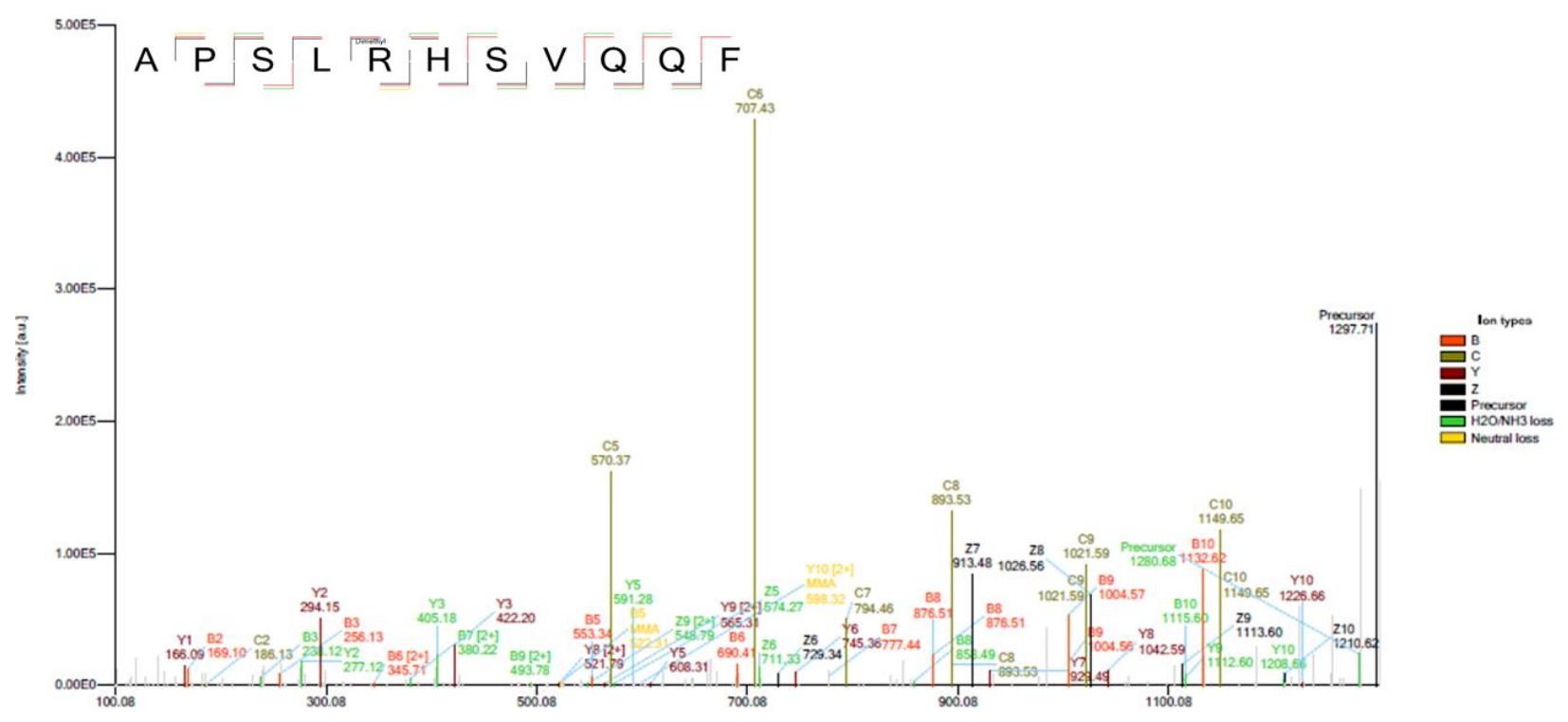

Supplementary Figure 18. EThcD spectra of the P5 symmetrycally dimethyl (SDMA)modified peptide APSLRHSVQQF from the protein of origin Chromodomain-helicase-DNA-binding protein 7 (CHD-7). The neutral losses specific for asymmetrical dimethylation (MMA) are pointed in yellowin the spectra. The peptide was predicted as a HLA-B*07 binder.

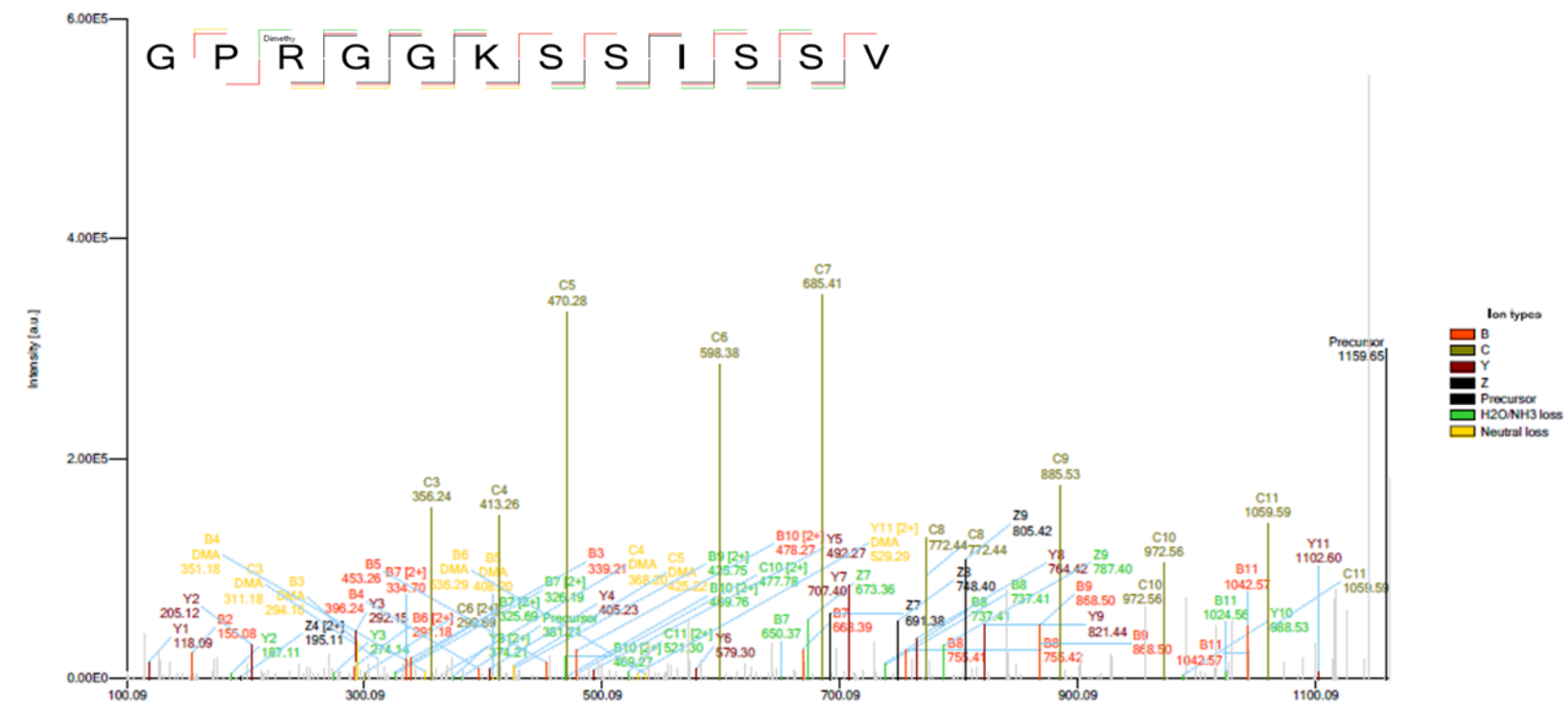

Supplementary Figure 19. EThcD spectra of the P3 asymmetrycally dimethyl (ADMA) modified peptide GPRGGKSSISSV from the protein of origin FragileX mental retardation syndrome-related protein 1 (hFXR1p). The 
neutral losses specific for asymmetrical dimethylation (DMA) are pointed in yellow in the spectra. The peptide was predicted as a HLA-B*07 binder.

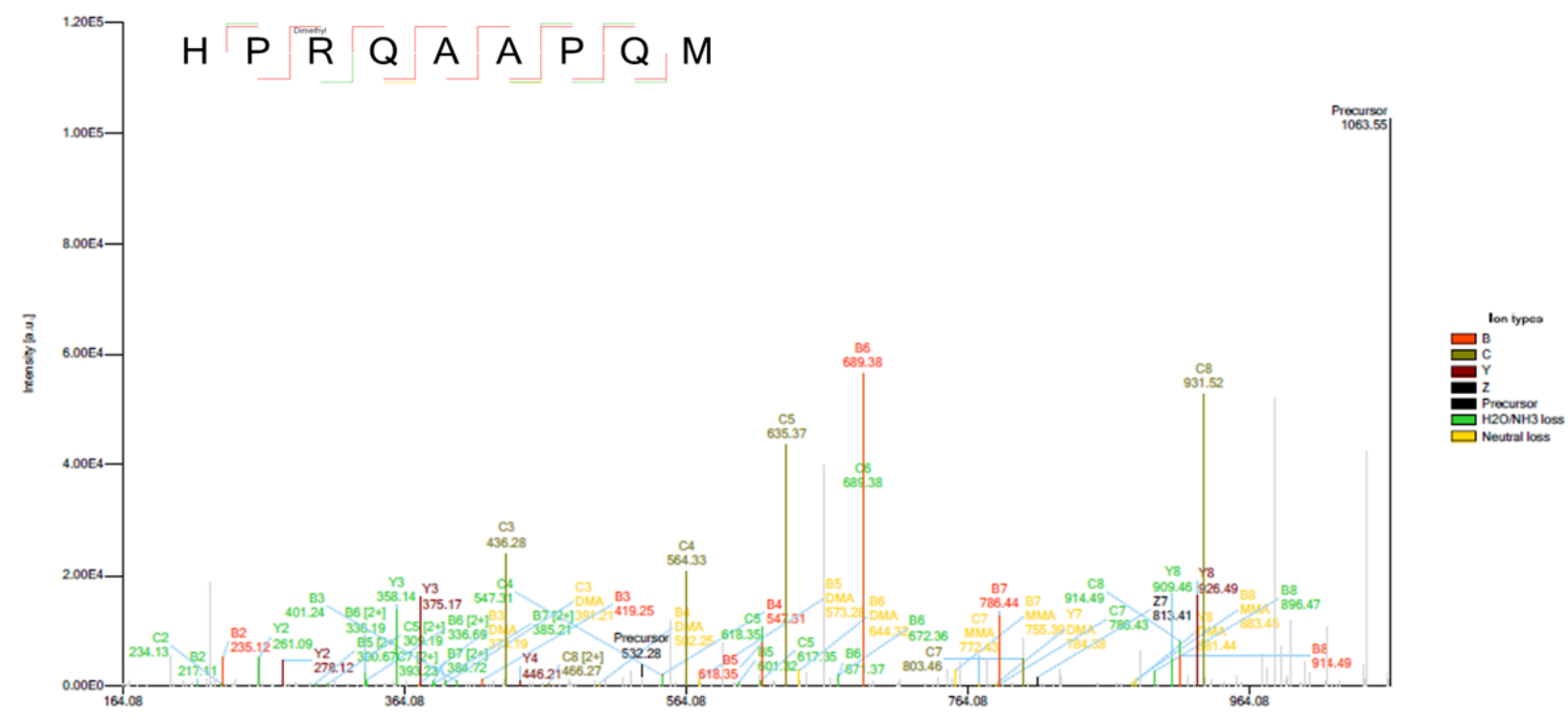

Supplementary Figure 20. EThcD spectra of the P3 asymmetrycally dimethyl (ADMA) modified peptide HPRQAAPQM from the protein of origin E3 ubiquitin-protein ligase TRIM33. The neutral losses specific for asymmetrical dimethylation (DMA) are pointed in yellow in the spectra. The peptide was predicted as a HLA-B*07 binder. 


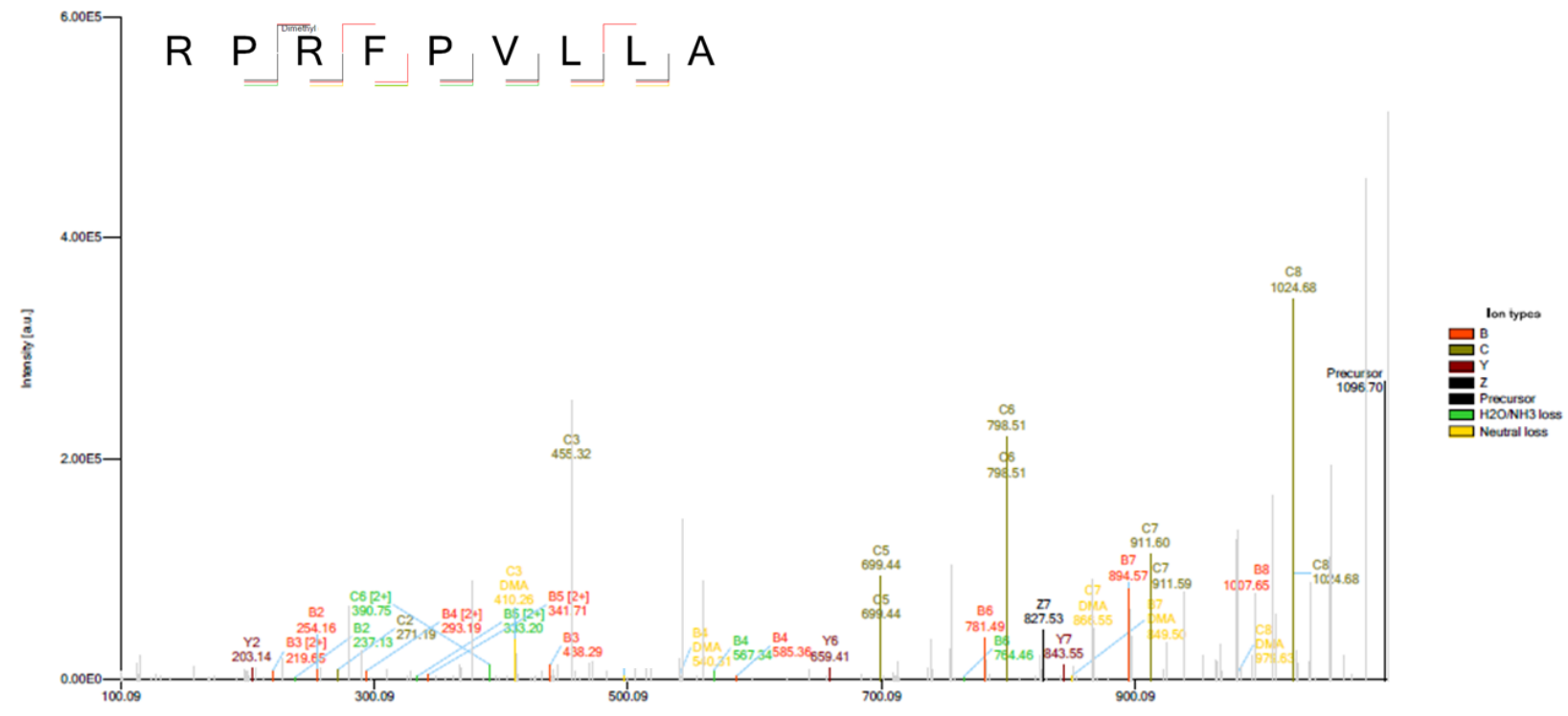

Supplementary Figure 21. EThcD spectra of the P3 asymmetrycally dimethyl (ADMA) modified peptide RPRFPVLLA from the protein of origin Double-stranded RNA-specific a denosine deaminase (DRADA). The neutral losses specific for asymmetrical dimethylation (DMA) are pointed in yellow in the spectra. The peptide was predicted as a HLAB*07 binder.

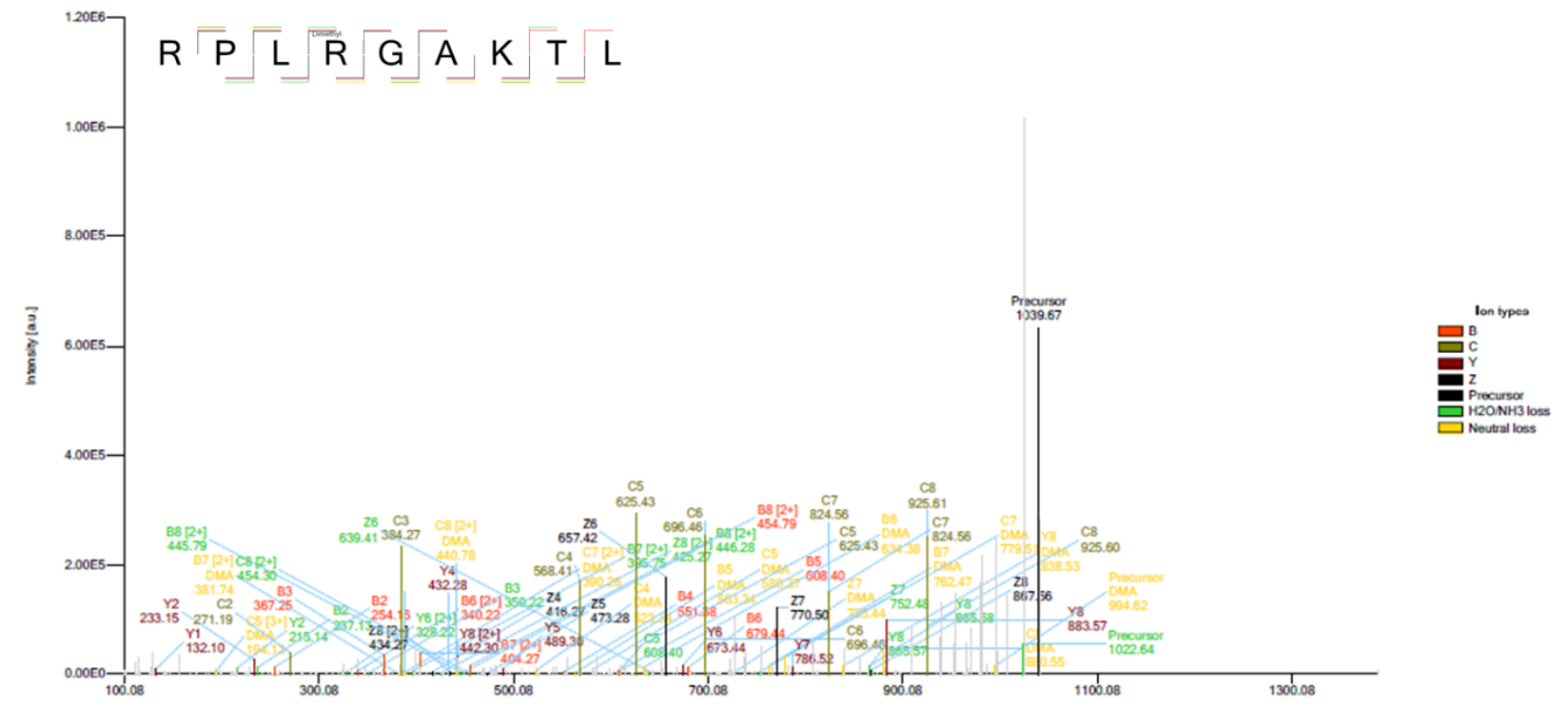

Supplementary Figure 22. EThcD spectra of the P4 asymmetrycally dimethyl (ADMA) modified peptide RPLRGAKTL from the protein of origin Ataxin-2-like protein (Ataxin-2 domain protein). The neutral losses specificfor 
asymmetrical dimethylation (DMA) are pointed in yellow in the spectra. The peptide was predicted as a HLA-B*07 binder.

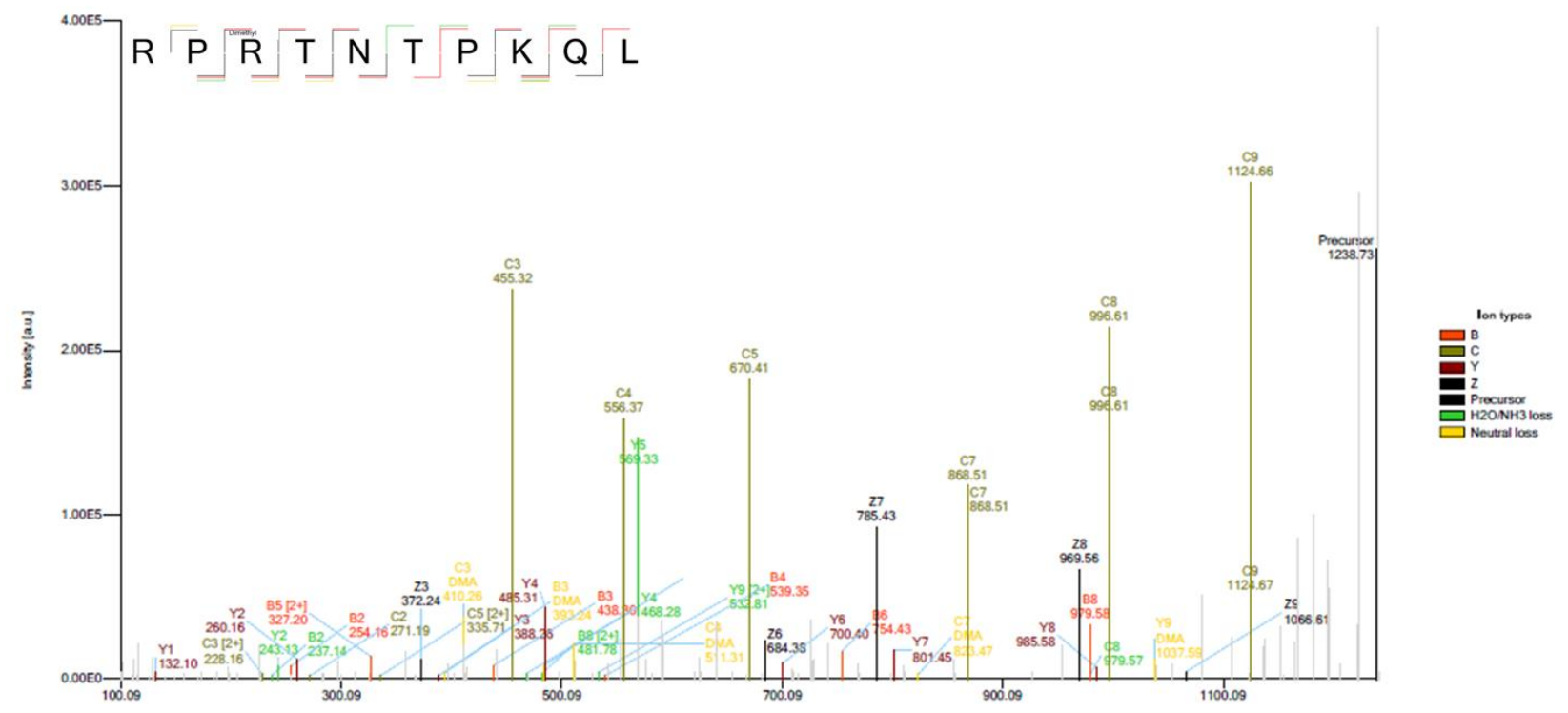

Supplementary Figure 23. EThcD spectra of the P3 asymmetrycally dimethyl (ADMA) modified peptide RPRTNTPKQL from the protein of origin Nuclear receptor coactivator 3 (NCOA-3). The neutral losses specific for asymmetrical dimethylation (DMA) are pointed in yellow in the spectra. The peptide was predicted as a HLA-B*07 binder. 


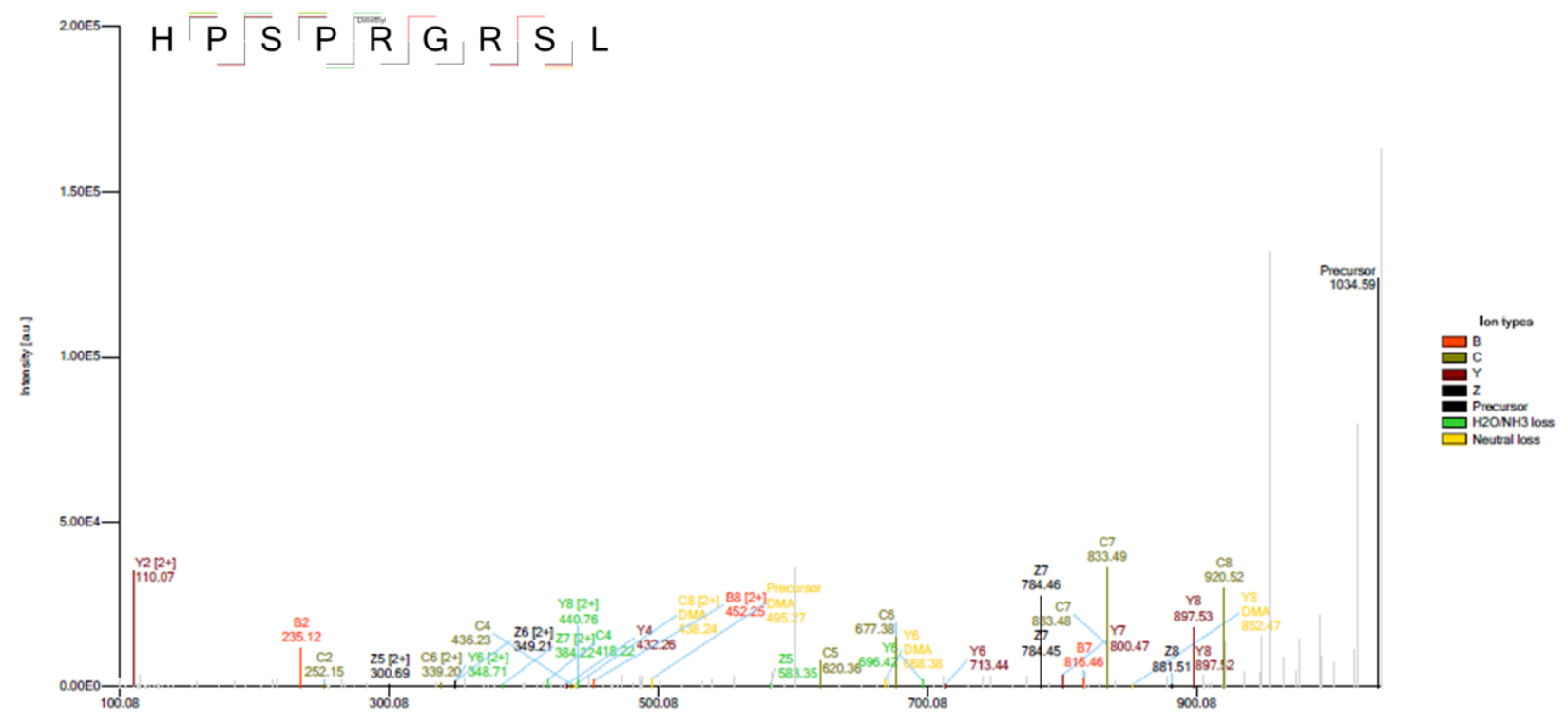

Supplementary Figure 24. EThcD spectra of the P5 asymmetrycally dimethyl (ADMA) modified peptide HPSPRGRSL

from the protein E3 ubiquitin-protein ligase TRIM33. The neutral losses specific for asymmetrical dimethylation (DMA) are pointed in yellow in the spectra. The peptide was predicted as a HLA-B*07 binder.

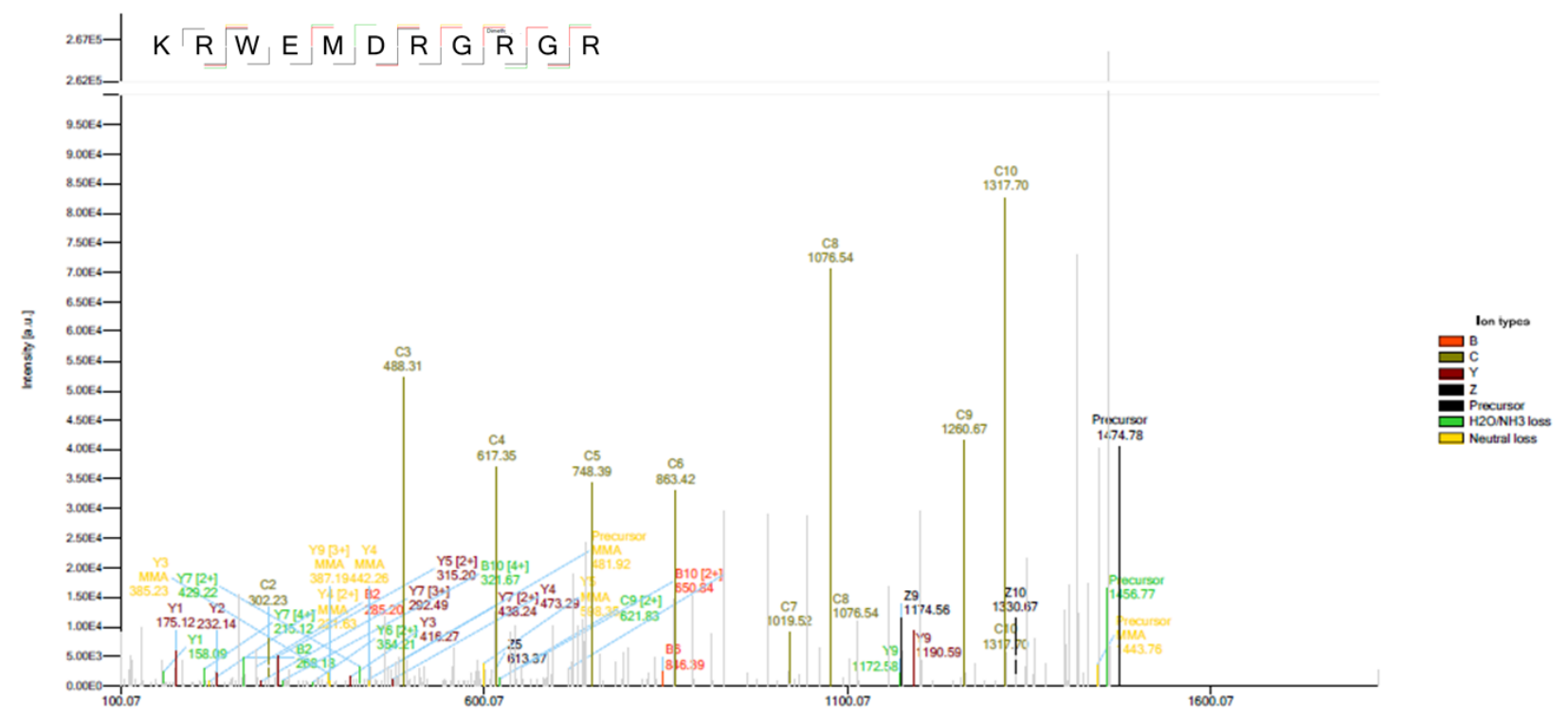

Supplementary Figure 25. EThcD spectra of the P9 symmetrycally dimethyl (SDMA) modified peptide KRWEMDRGRGR from the protein Suppressor of SWI4 1 homolog (Ssf-1). The neutral losses specificfor 
symmetrical dimethylation (MMA) are pointed in yellowin the spectra. The peptide was predicted as a HLA-B*27 binder.

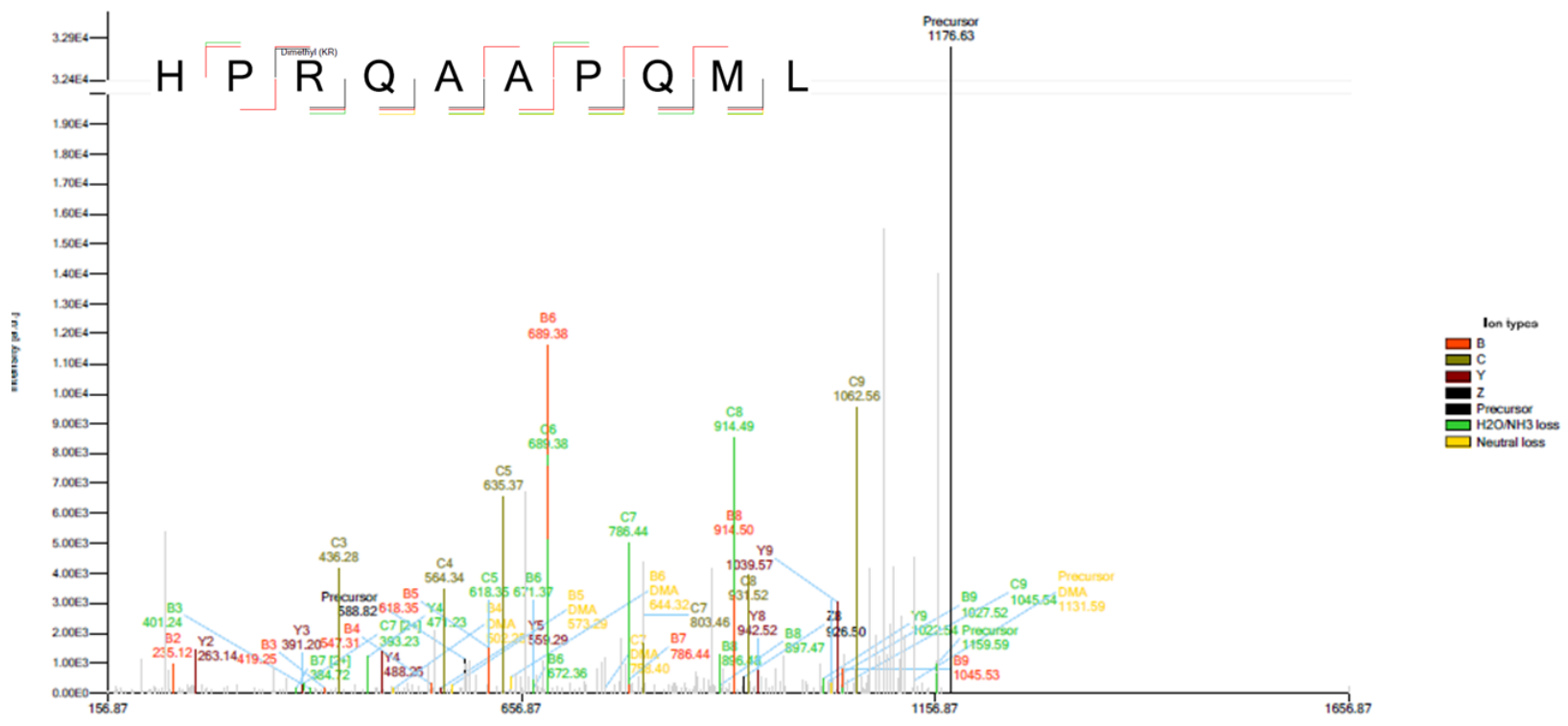

Supplementary Figure 26. EThcD spectra of the P3 asymmetrycally dimethyl (ADMA) modified peptide HPRQAAPQML from the protein E3 ubiquitin-protein ligase TRIM33. The neutral losses specific for asymmetrical dimethylation (DMA) are pointed in yellow in the spectra. The peptide was predicted as a HLA-B*07 binder. 


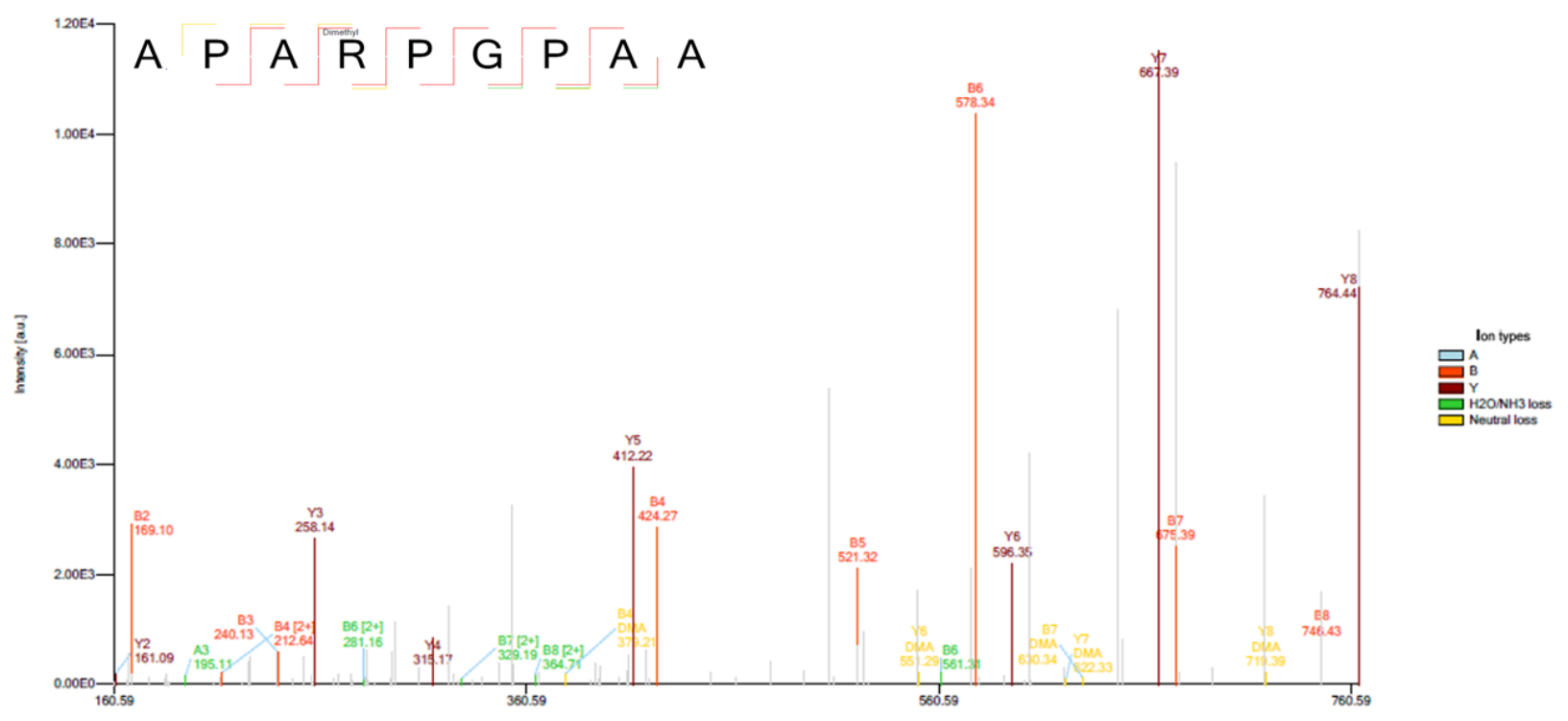

Supplementary Figure 27. HCD spectra of the P4 asymmetrycally dimethyl (ADMA) modified peptide APARPGPAA from the protein Eukaryotic translation initiation factor 4 gamma 1 (elF-4-gamma 1). The neutral losses specific for asymmetrical dimethylation (DMA) are pointed in yellow in the spectra. The peptide was predicted as a HLA-B*07 binder.

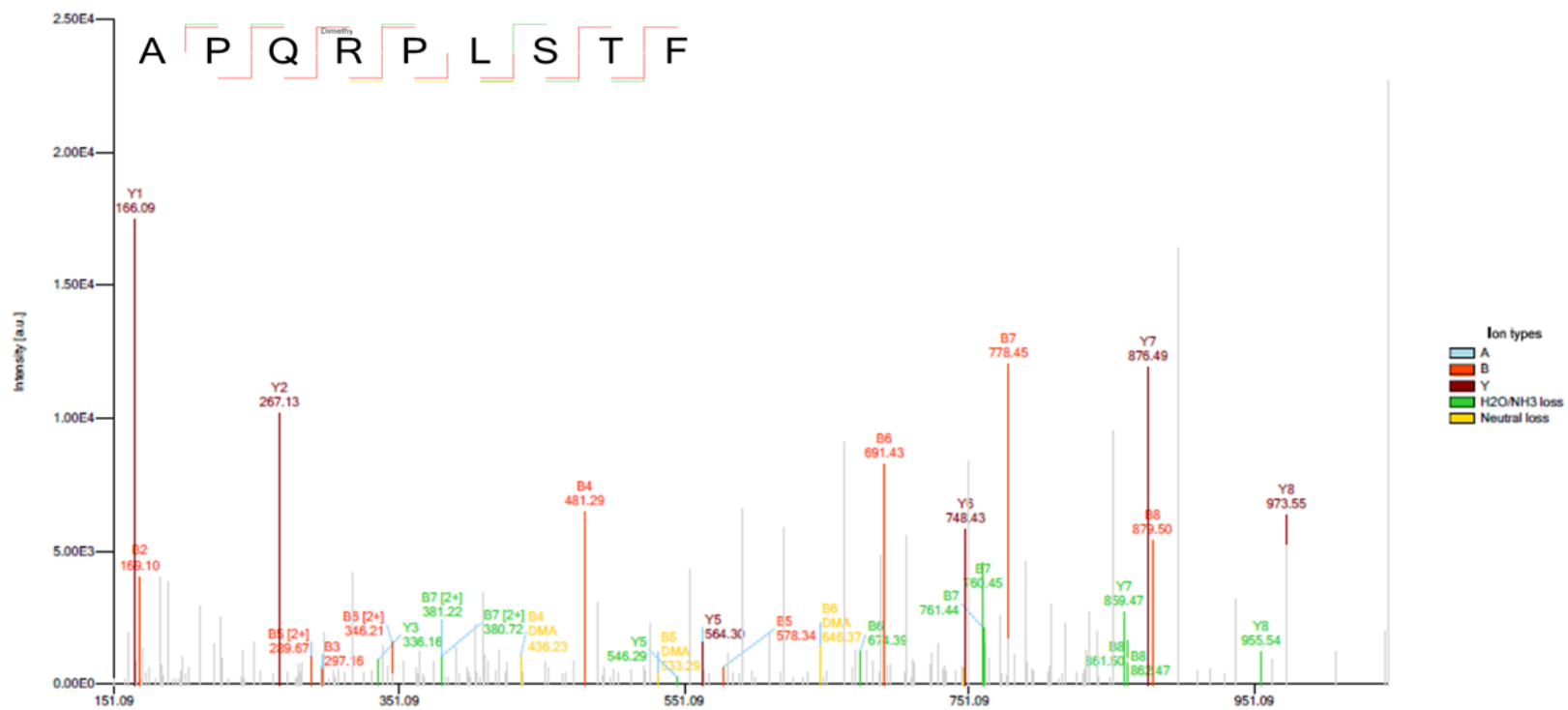

Supplementary Figure 28. HCD spectra of the P4 asymmetrycally dimethyl (ADMA) modified peptide APQRPLSTF 
from the protein Transcription factor 19 (TCF-19). The neutral loss es specific for asymmetrical dimethylation (DMA) are pointed in yellowin the spectra. The peptide was predicted as a HLA-B*07 binder.

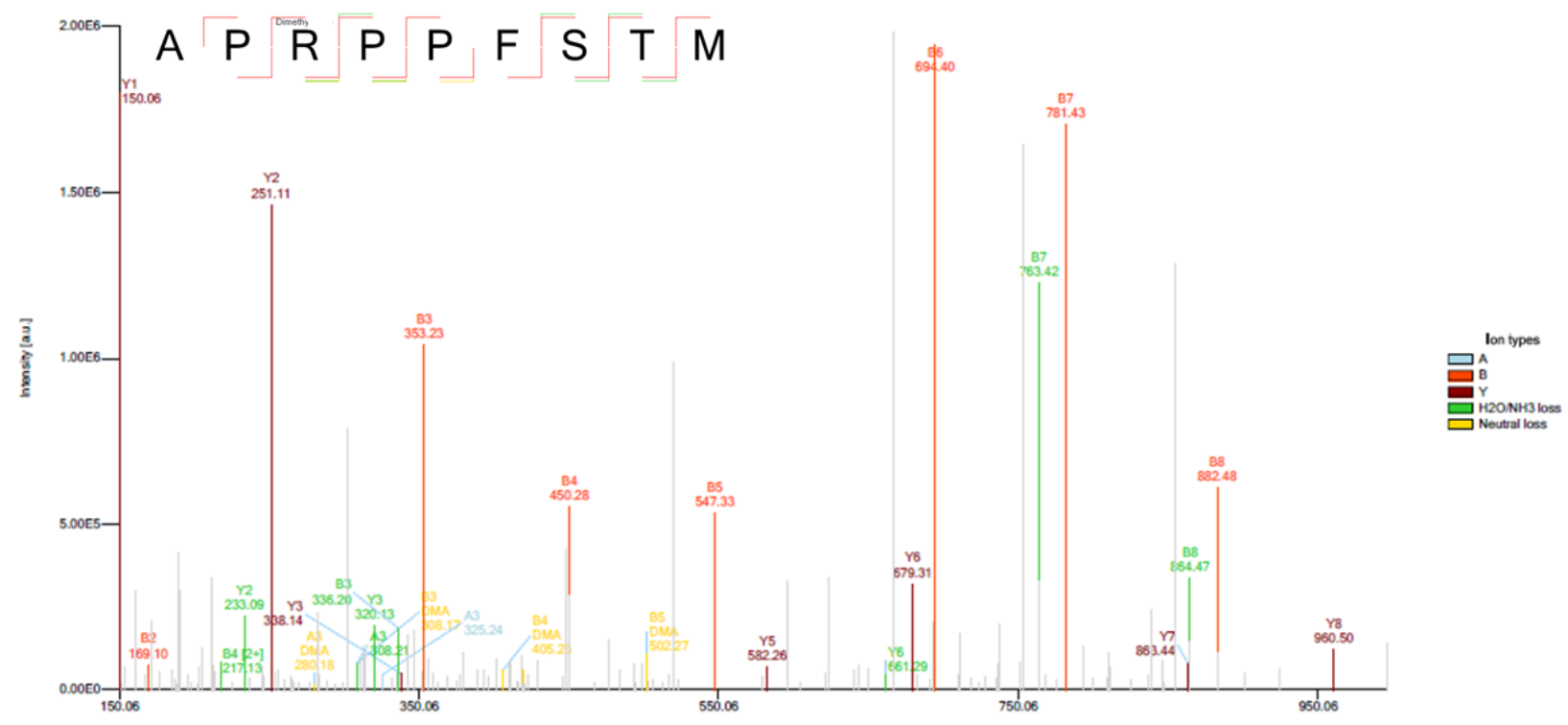

Supplementary Figure 29. HCD spectra of the P3 asymmetrycally dimethyl (ADMA) modified peptide APRPPFSTM from the protein Polyadenylate-binding protein 1 (PABP-1). The neutral losses specific for asymmetrical dimethylation (DMA) are pointed in yellow in the spectra. The peptide was predicted as a HLA-B*07 binder. 


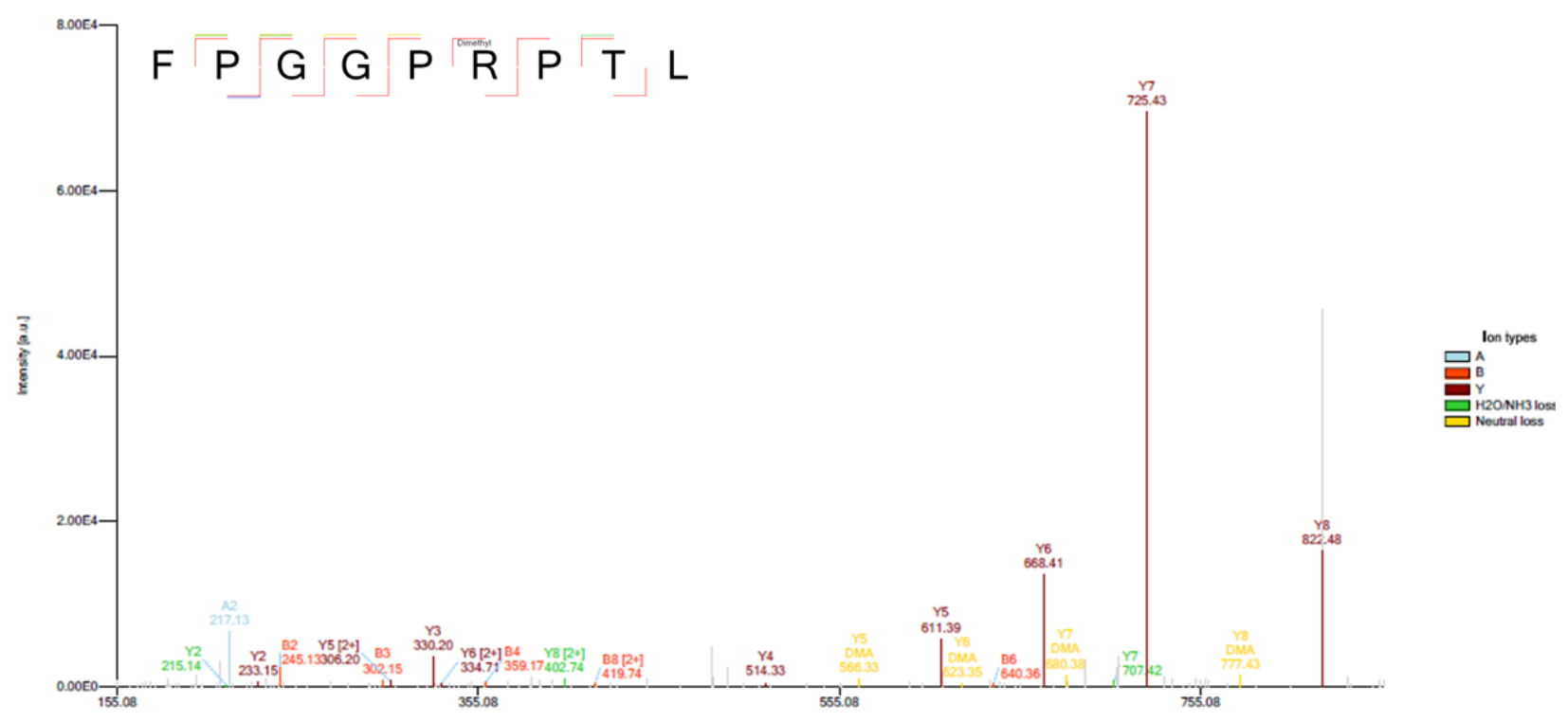

Supplementary Figure 30. CID spectra of the P6 asymmetrycally dimethyl (ADMA) modified peptide FPGGPRPTL from the Single-stranded DNA-binding protein. The neutral losses specific for asymmetrical dimethylation (DMA) are pointed in yellow in the spectra. The peptide was predicted as a HLA-B*07 binder.

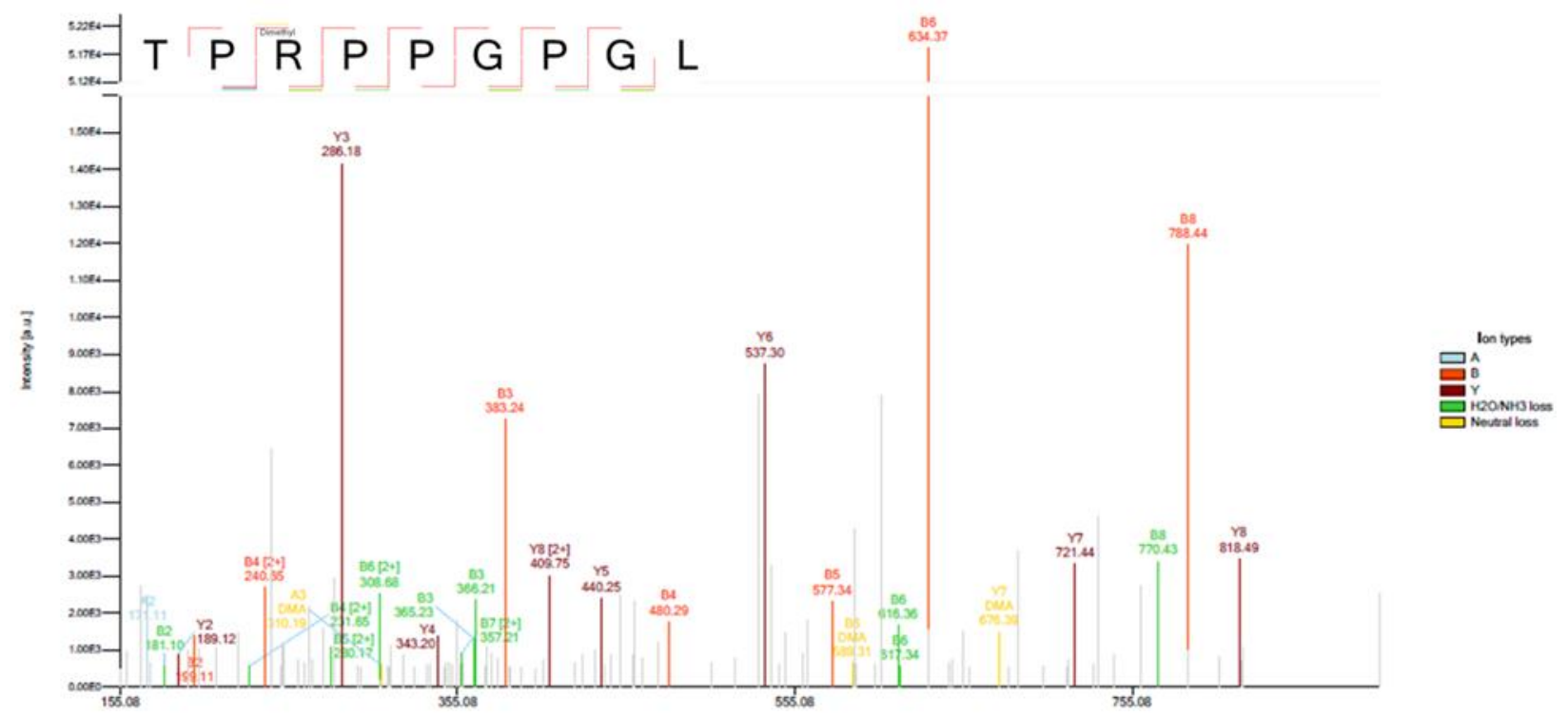

Supplementary Figure 31. HCD spectra of the P3 asymmetrycally dimethyl (ADMA) modified peptide TPRPPGPGL from the Histone-lysine N-methyltransferase 2C (Lysine N-methyltransferase 2C). The neutral losses specificfor 
asymmetrical dimethylation (ADMA) are pointed in yellowin the spectra. The peptide was predicted as a HLA-B*07 binder.

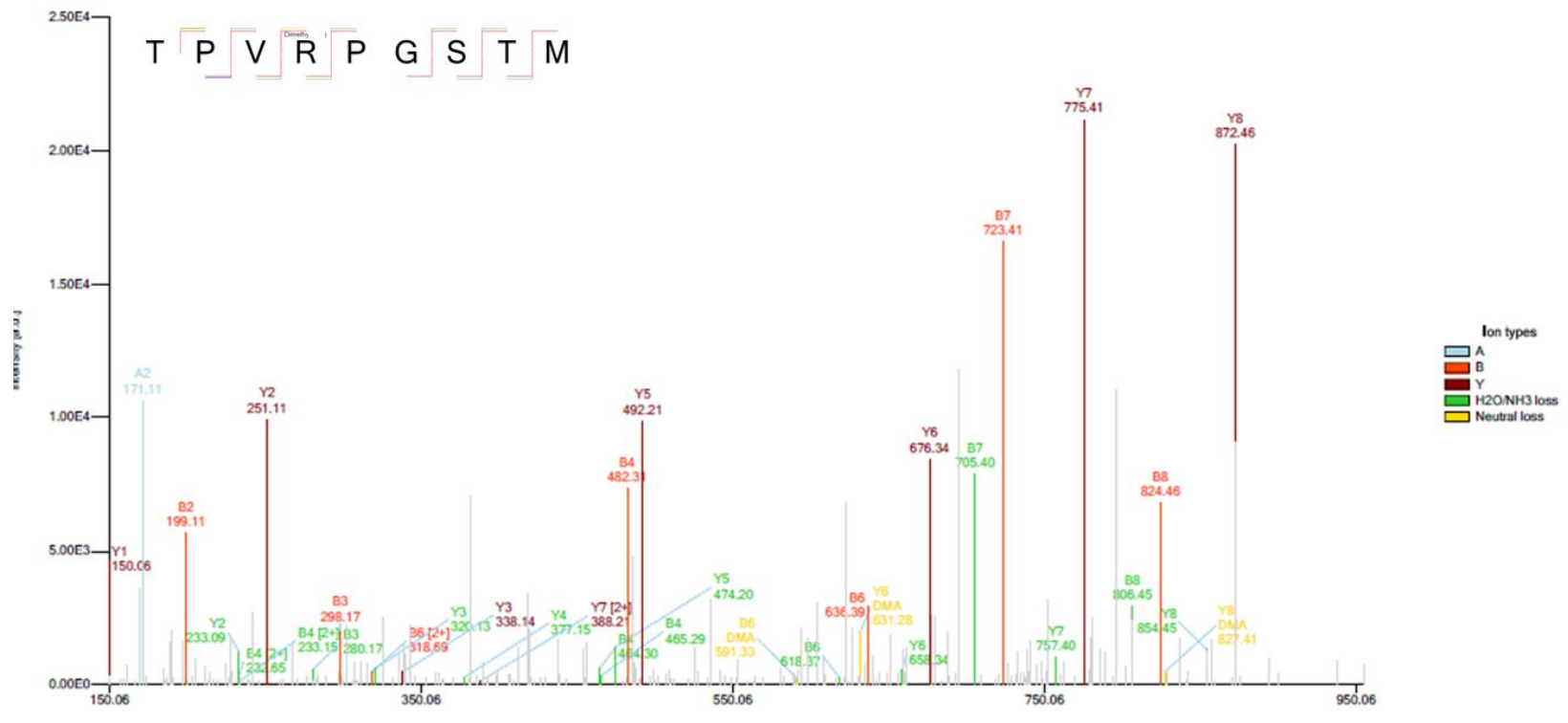

Supplementary Figure 32. HCD spectra of the P4 asymmetrycally dimethyl (ADMA) modified peptide TPVRPGSTM

from the protein Pogo transposable element with ZNF domain. The neutral losses specific for asymmetrical dimethylation (DMA) are pointed in yellow in the spectra. The peptide was predicted as a HLA-B*07 binder. 


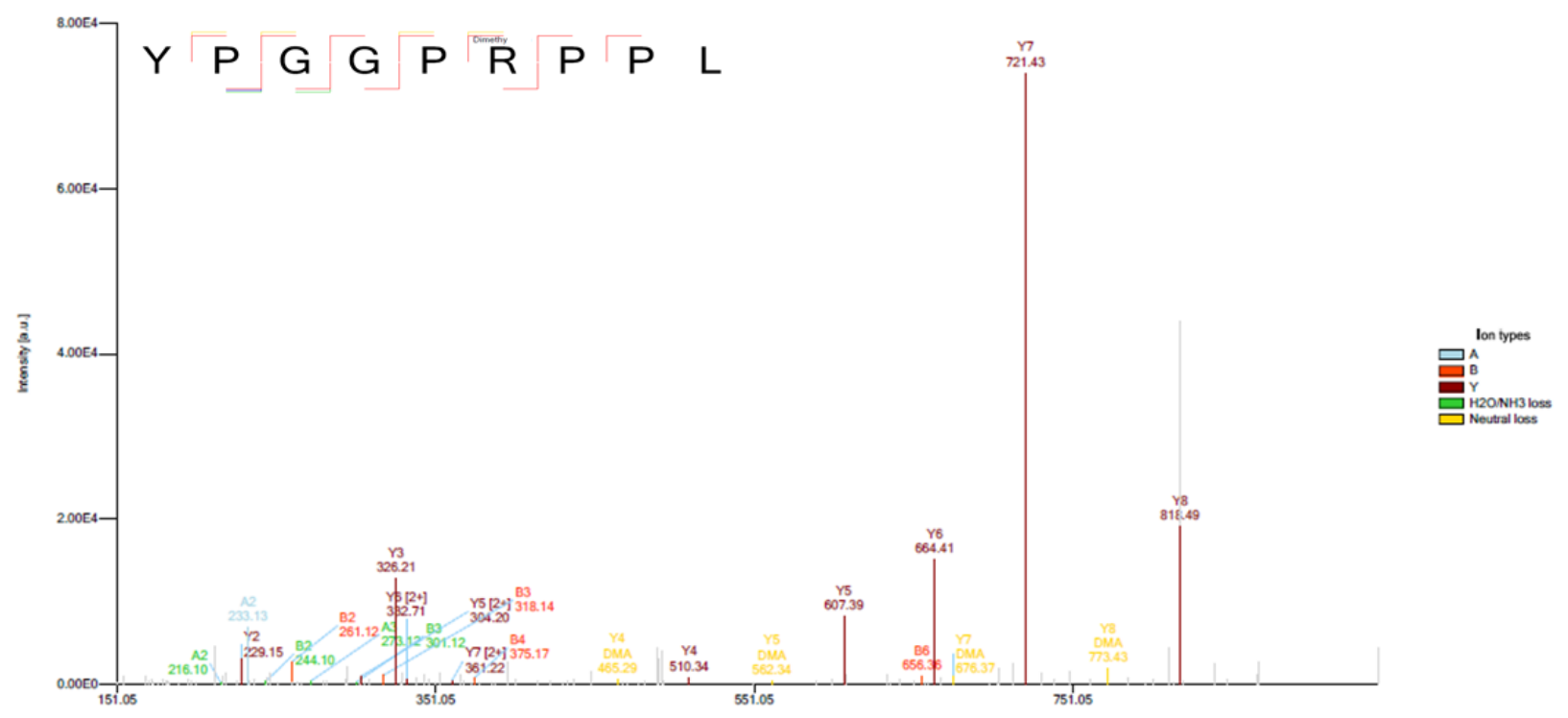

Supplementary Figure 33. CID spectra of the P6 asymmetrycally dimethyl (ADMA) modified peptide YPGGPRPPL from the protein Single-stranded DNA-binding protein 2 (Sequence-specific single-stranded-DNA-binding protein 2). The neutral losses specific for asymmetrical dimethylation (DMA) are pointed in yellow in the spectra. The peptide was predicted as a HLA-B*07 binder.

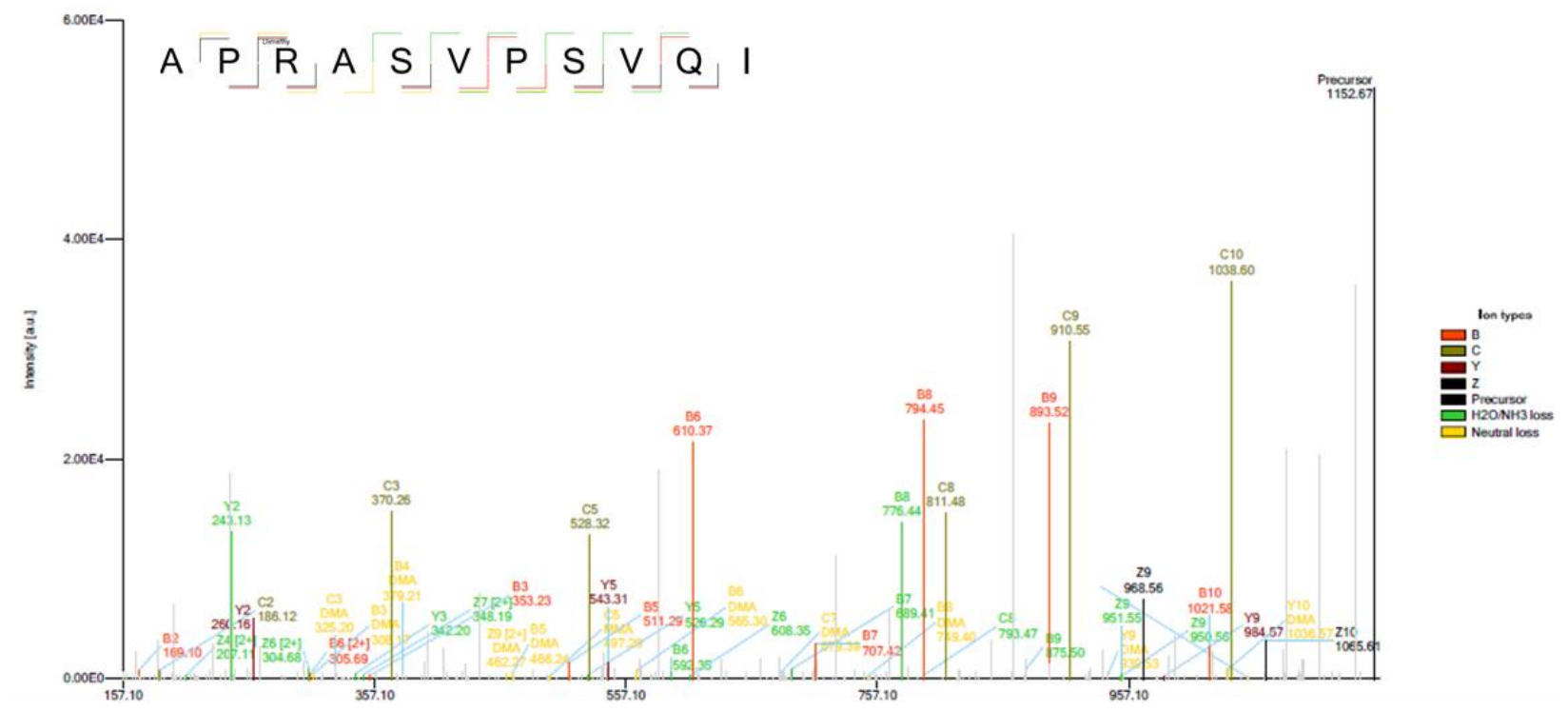

Supplementary Figure 34. EThcD spectra of the P3 asymmetrycally dimethyl (ADMA) modified peptide 
APRASVPSVQI from the protein Transcriptional repressor p66-alpha (Hp66alpha). The neutral losses specific for asymmetrical dimethylation (DMA) are pointed in yellow in the spectra. The peptide was predicted as a HLA-B*07 binder.

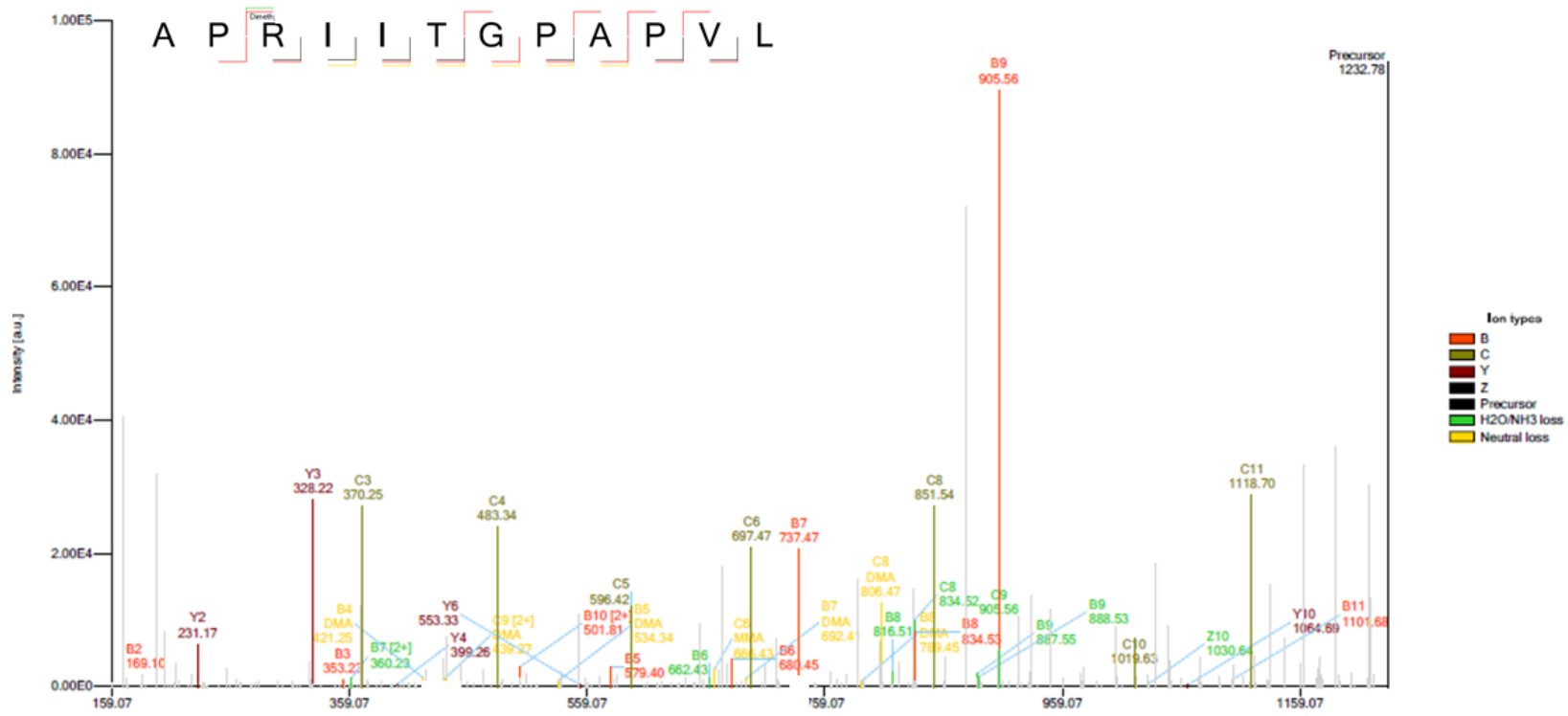

Supplementary Figure 35. EThcD spectra of the P3 asymmetrycally dimethyl (ADMA) modified peptide APRIITGPAPVL from the Protein quaking (Hqk). The neutral losses specific for asymmetrical dimethylation (DMA) are pointed in yellow in the spectra. The peptide was predicted as a HLA-B*07 binder. 


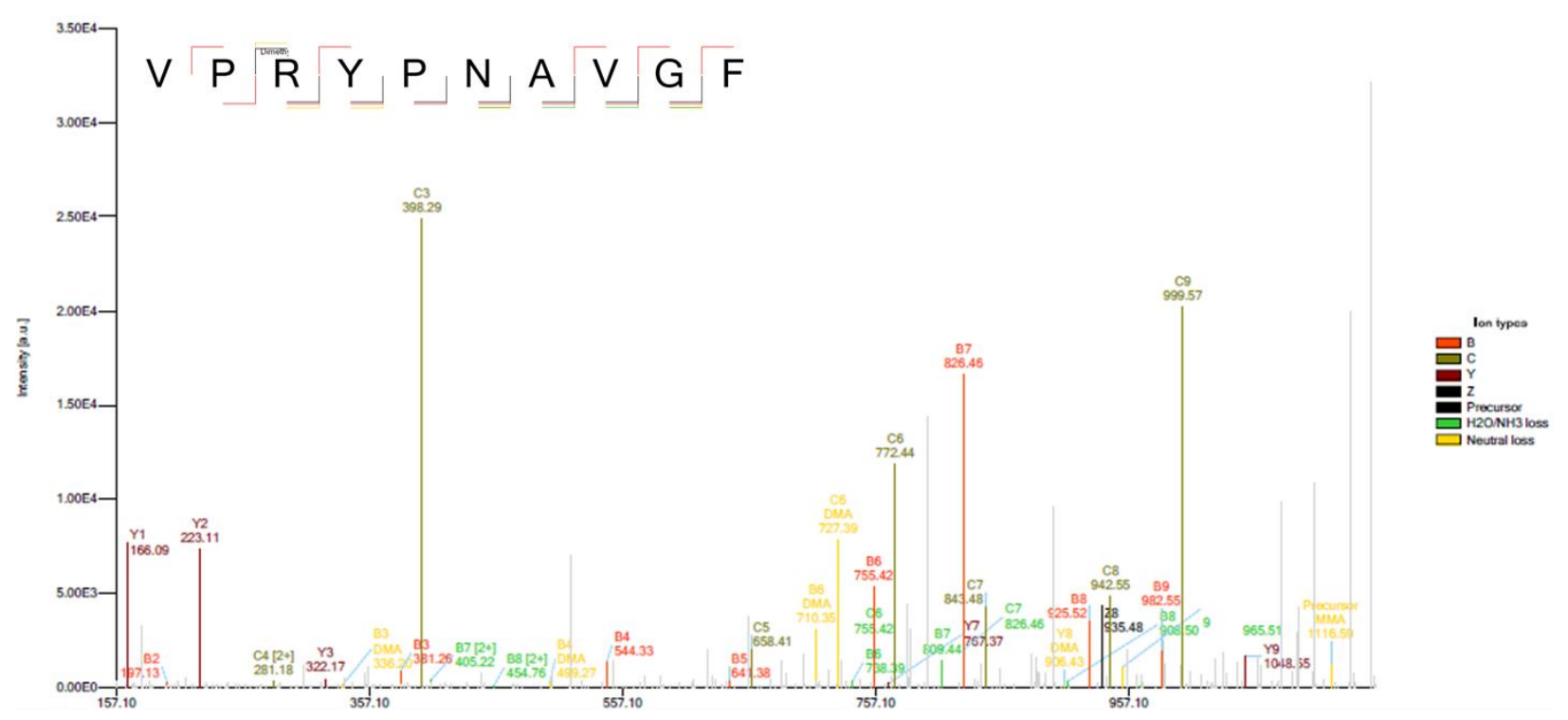

Supplementary Figure 36. EThcD spectra of the P3 asymmetrycally dimethyl (ADMA) modified peptide VPRYPNAVGF from the Chromodomain-helicase-DNA-binding protein 7 (CHD-7). The neutral losses specific for asymmetrical dimethylation (DMA) are pointed in yellow in the spectra. The peptide was predicted as a HLA-B*07 binder.

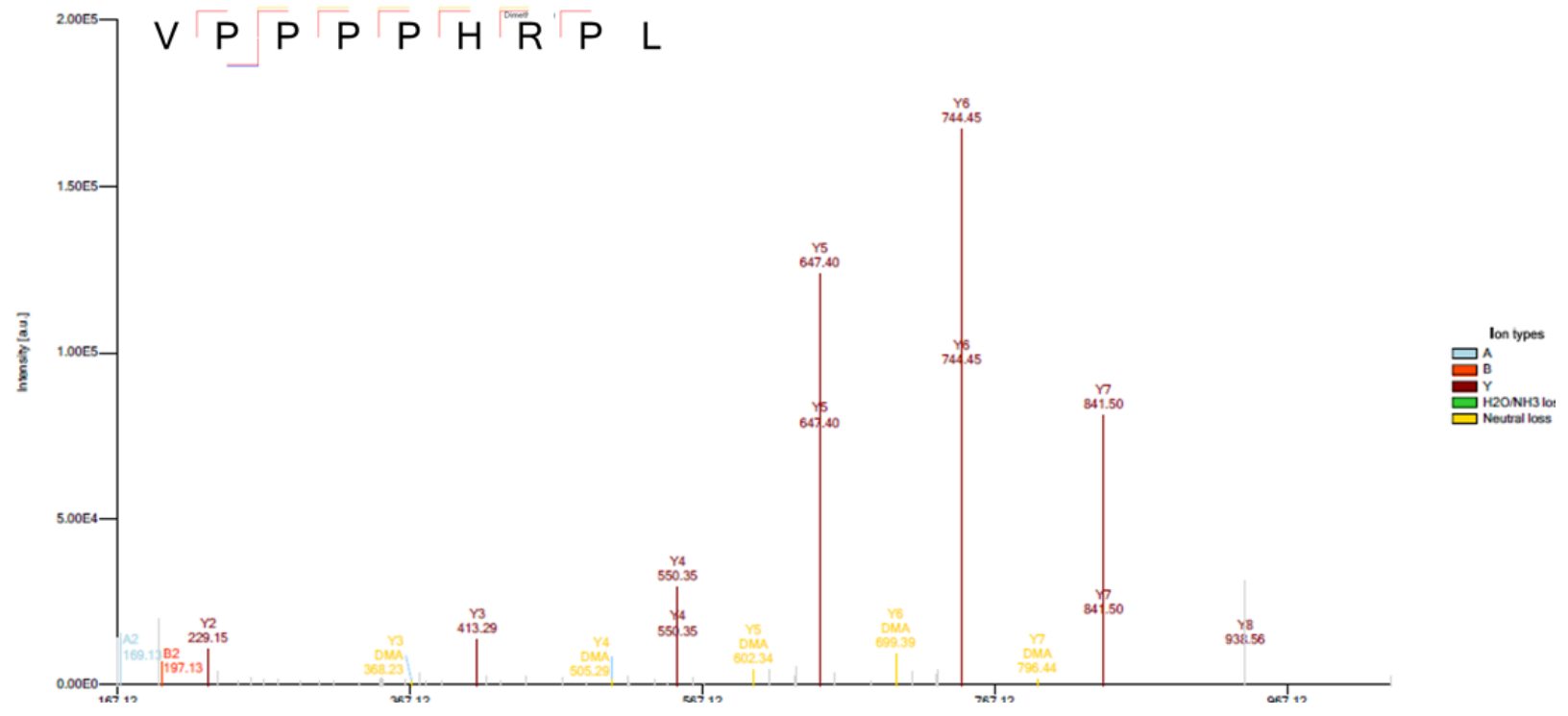

Supplementary Figure 37. HCD spectra of the P7 asymmetrycally dimethyl (ADMA) modified peptide VPPPPHRPL 
from the Protein PRRC2C. The neutral losses specific for asymmetrical dimethylation (DMA) are pointed in yellow in the spectra. The peptide was predicted as a HLA-B*07 binder.

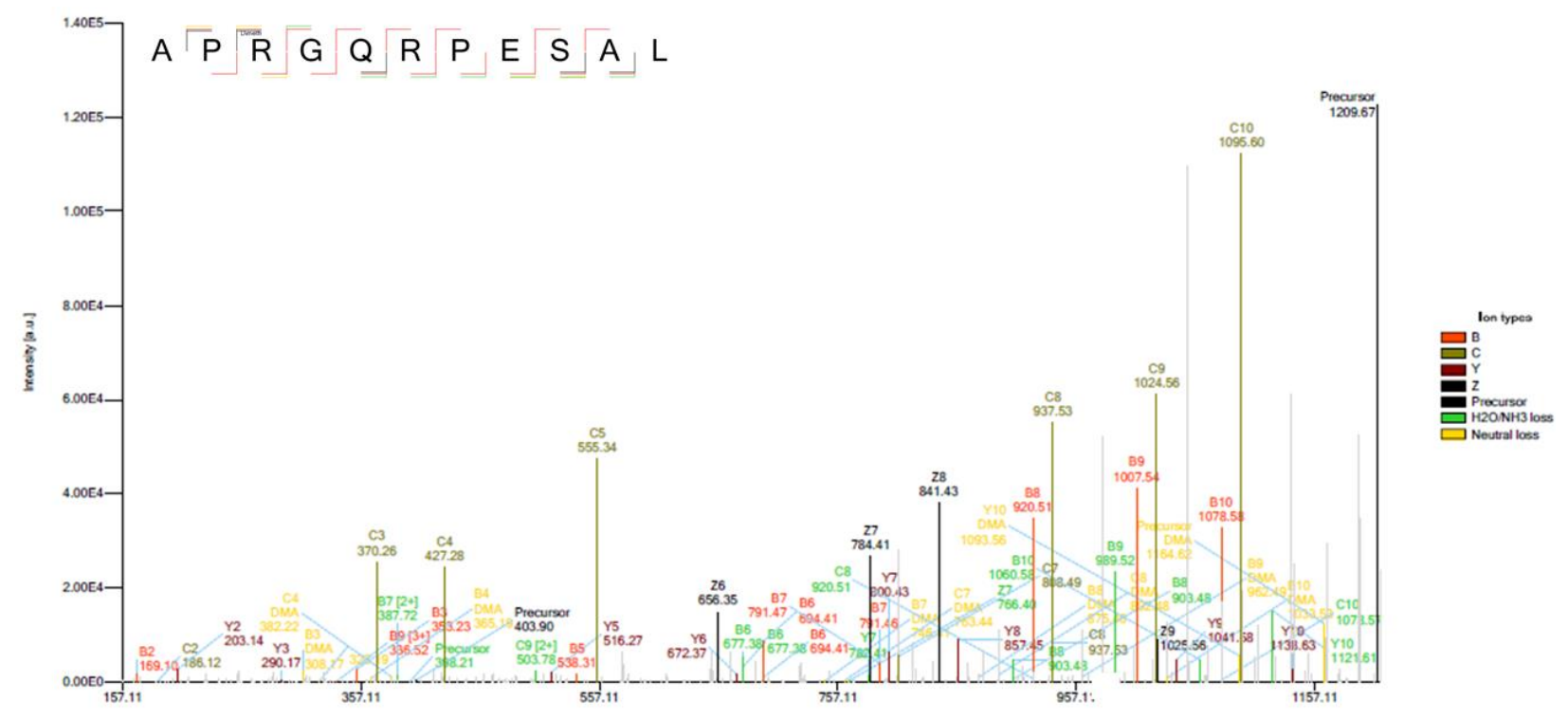

Supplementary Figure 38. EThcD spectra of the P3 asymmetrycally dimethyl (ADMA) modified peptide APRGQRPESAL from the Proteasome subunit beta type-8. The neutral losses specific for asymmetrical dimethylation (DMA) are pointed in yellow in the spectra. The peptide was predicted as a HLA-B*07 binder. 


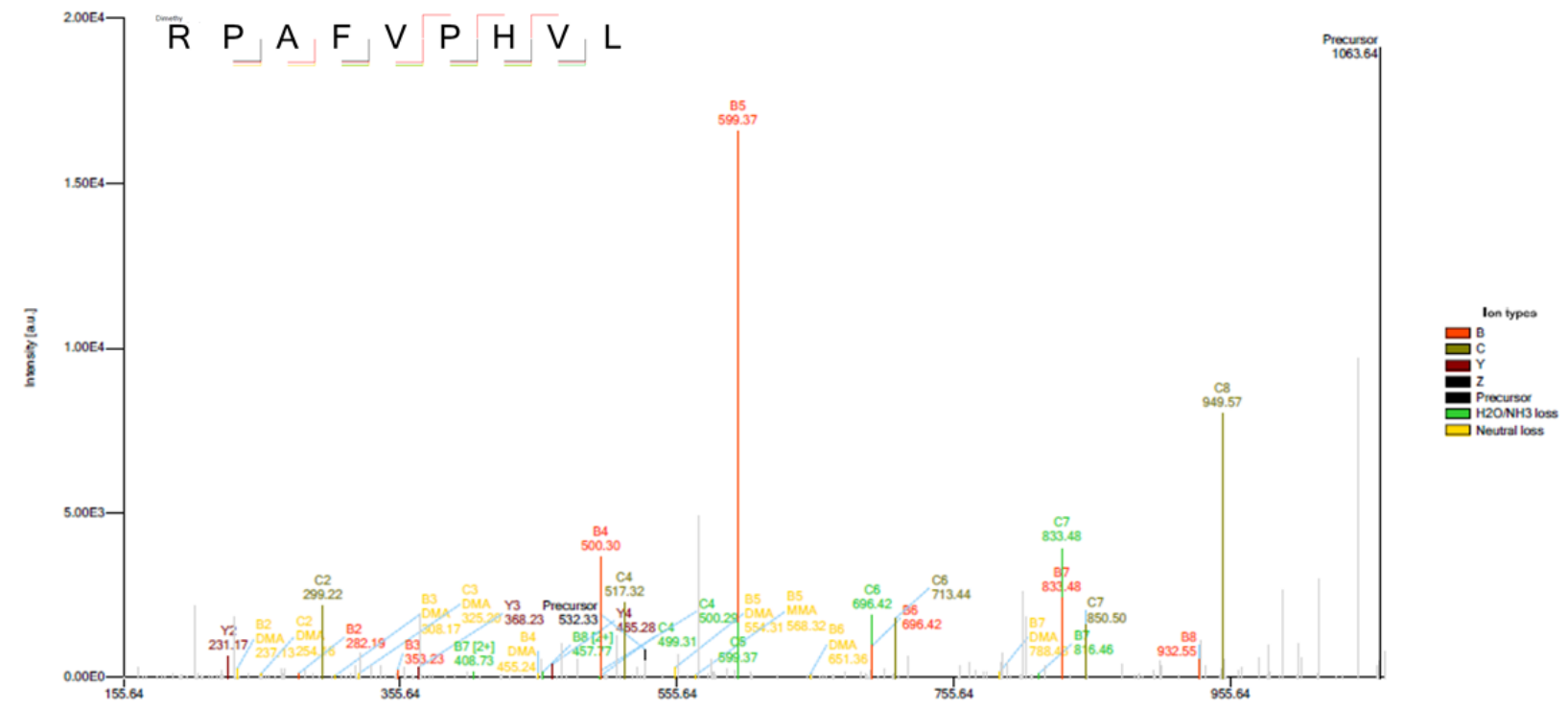

Supplementary Figure 39. EThcD spectra of the P1 asymmetrycally dimethyl (ADMA) modified peptide RPAFVPHVL from the RNA-binding protein 42 (RNA-binding motif protein 42). The neutral losses specificfor asymmetrical dimethylation (DMA) are pointed in yellow in the spectra. The peptide was predicted as a HLA-B*07 binder.

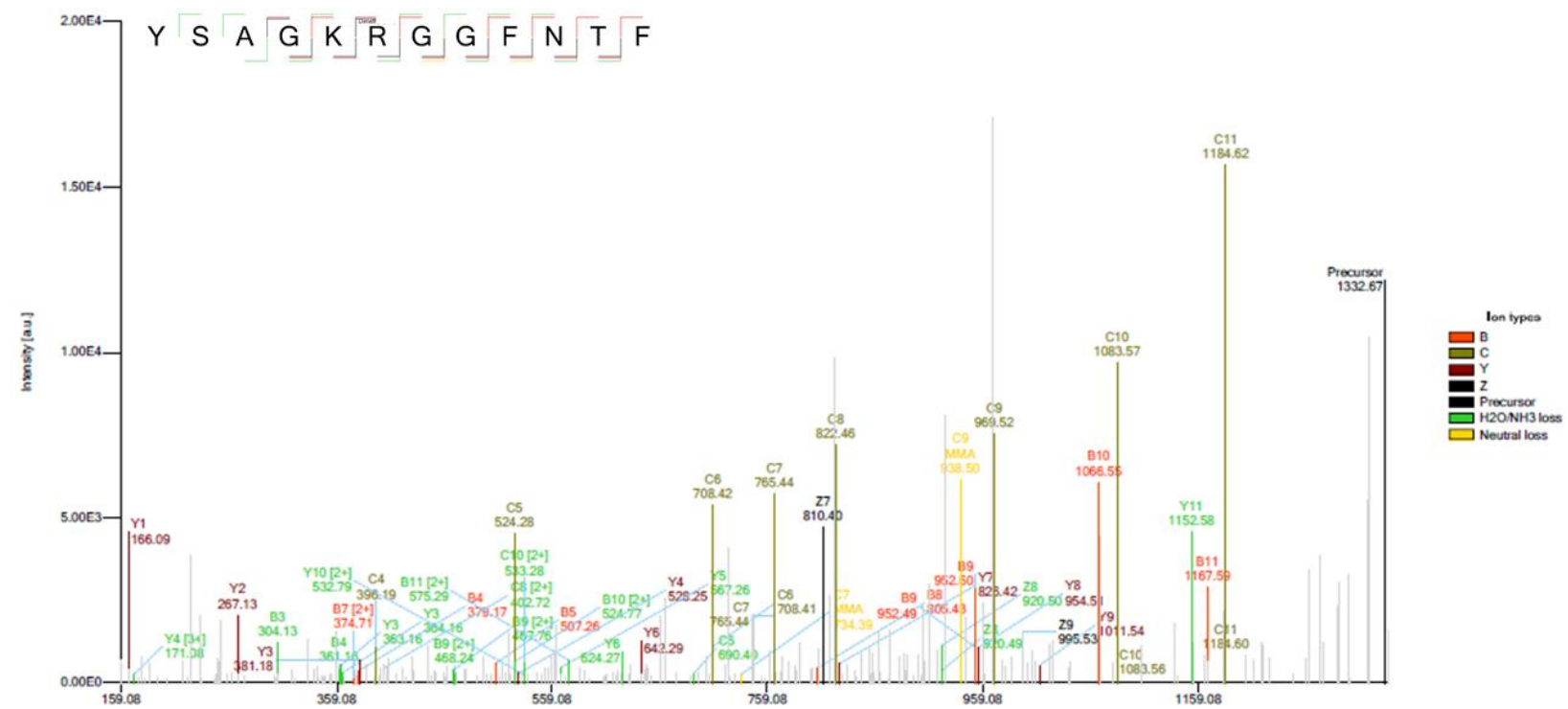

Supplementary Figure 40. EThcD spectra of the P6 symmetrycally dimethyl (ADMA) modified peptide YSAGKRGGFNTF from the ProbableATP-dependent RNA helicase DDX5. The neutral losses specific for asymmetrical dimethylation (MMA) are pointed in yellowin the spectra. 


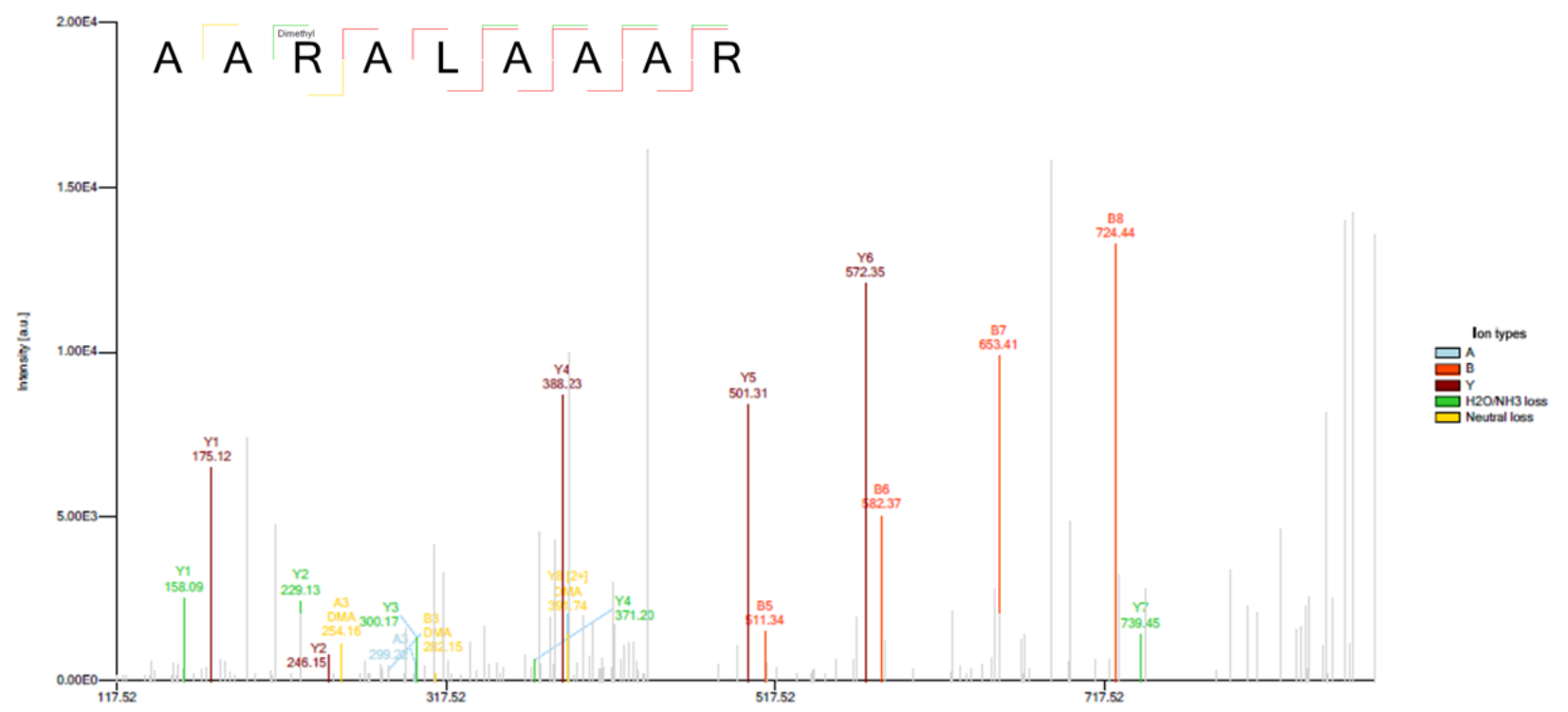

Supplementary Figure 41. HCD spectra of the P3 asymmetrycally dimethyl (ADMA) modified peptide AARALAAR

from the GAS2-like protein 1 (GAS2-related protein on chromosome). The neutral loss es specific for asymmetrical dimethylation (DMA) are pointed in yellow in the spectra. The peptide was predicted as a HLA-B*07 binder.

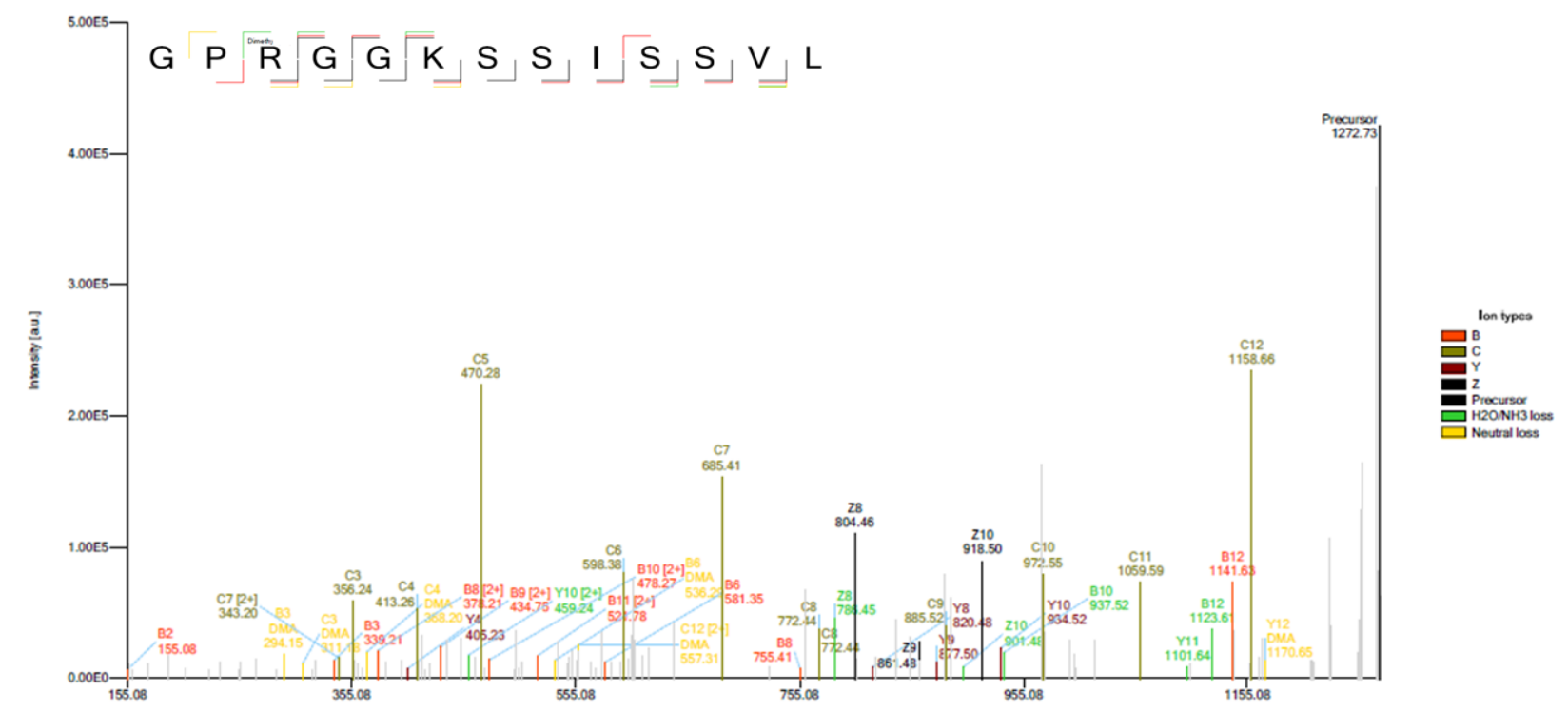

Supplementary Figure 42. EThcD spectra of the P3 asymmetrycally dimethyl (ADMA) modified peptide 
GPRGGKSSISSVL from the FragileX mental retardation syndrome-related protein 1 (hFXR1p). The neutral losses specific for asymmetrical dimethylation (DMA) are pointed in yellow in the spectra. The peptide was predicted as a HLA-B*07 binder.

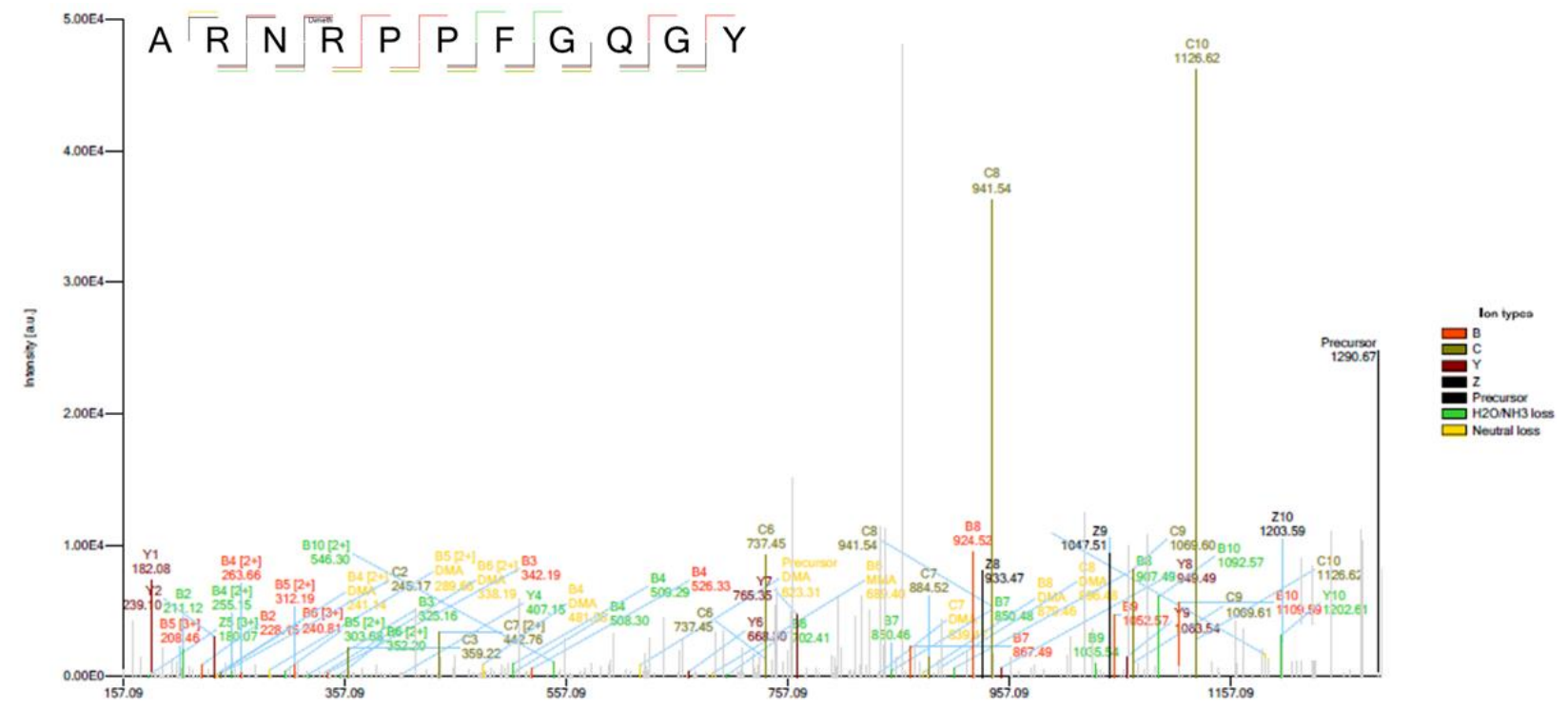

Supplementary Figure 43. EThcD spectra of the P4 asymmetrycally dimethyl (ADMA) modified peptide ARNRPPFGQGY from the Protein TFG (TRK-fused gene protein). The neutral losses specific for asymmetrical dimethylation (DMA) are pointed in yellow in the spectra. The peptide was predicted as a HLA-B*27 binder. 


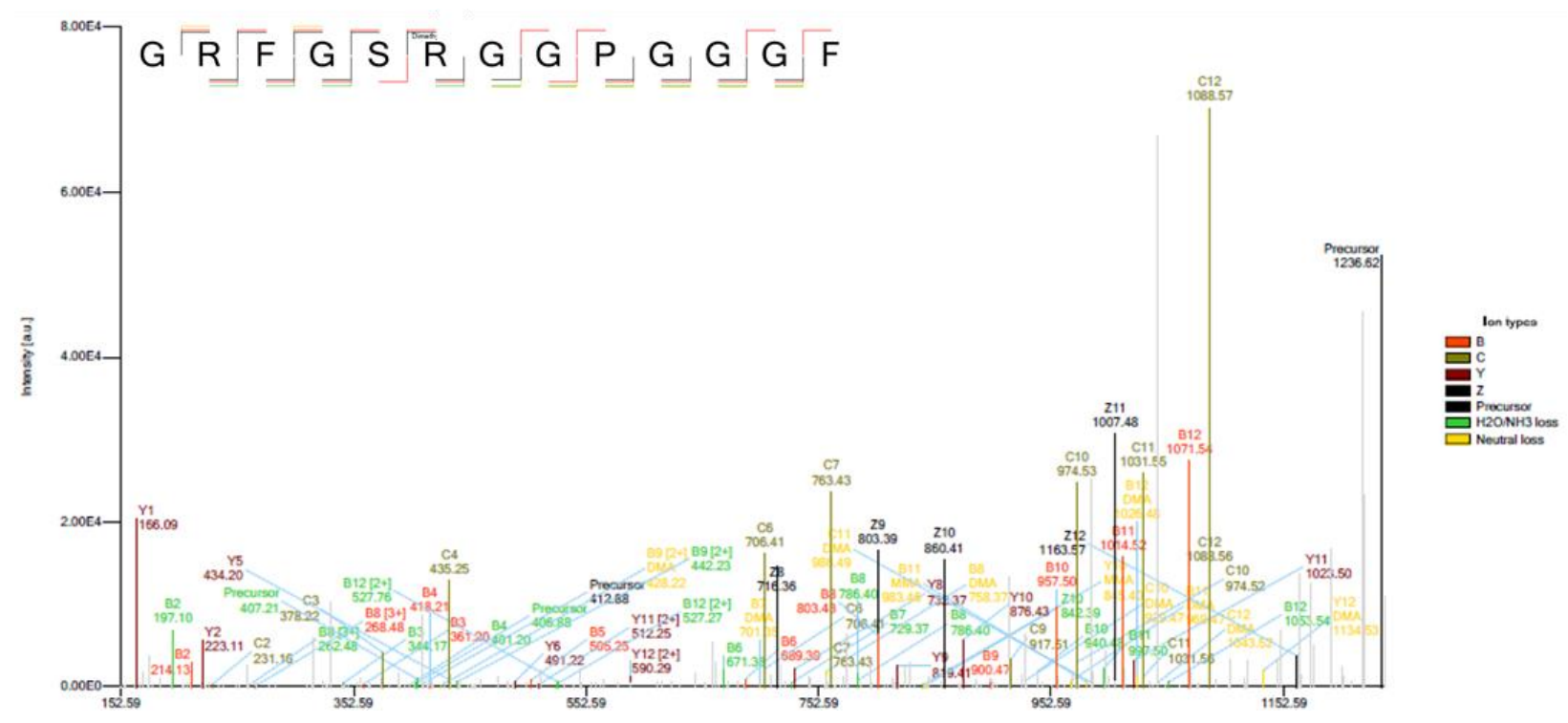

Supplementary Figure 44. EThcD spectra endogenous P6 asymmetrycally dimethyl (ADMA) modified peptide GRFGSRGGPGGGF from Interleukin enhancer-binding factor 2. The neutral losses specificfor asymmetrical dimethylation (DMA) are pointed in yellow in the spectra.

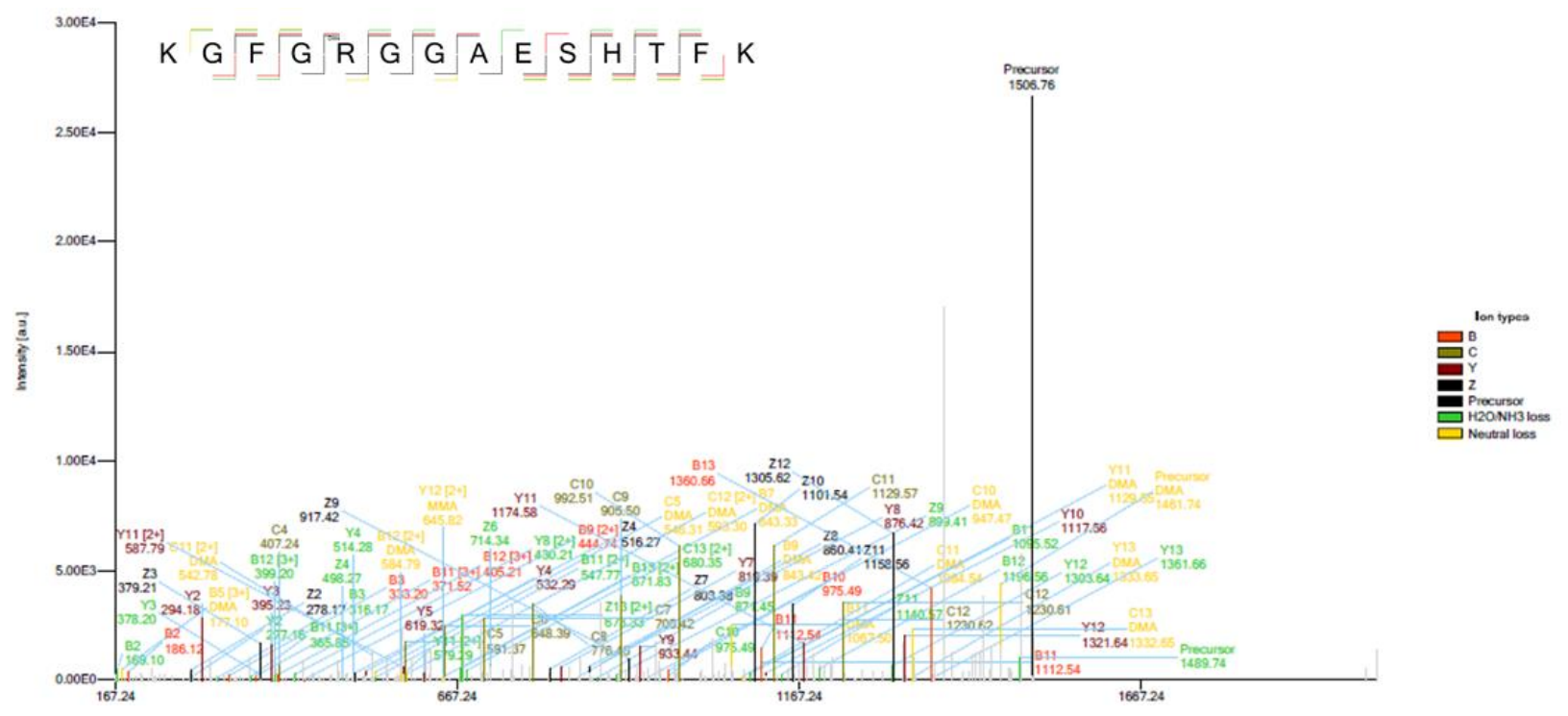

Supplementary Figure 45. EThcD spectra of the P5 asymmetrycally dimethyl (ADMA) modified peptide KGFGRGGAESHTFK from the Cysteine-rich protein 1 (CRP-1) (Cysteine-rich heart protein). The neutral losses specific 
for asymmetrical dimethylation (DMA) are pointed in yellow in the spectra. The peptide was predicted as a HLAA*03 binder.

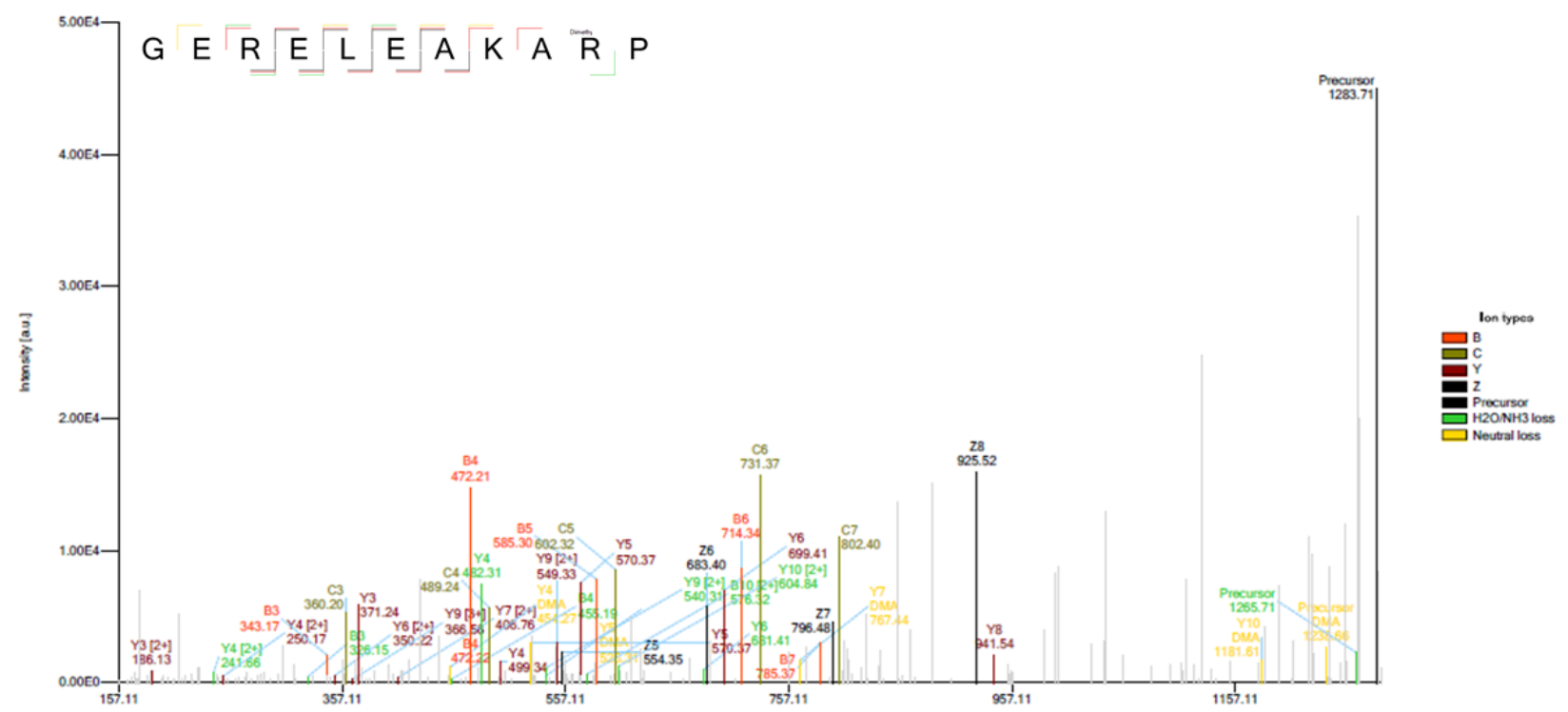

Supplementary Figure 46. EThcD spectra of the P10 asymmetrycally dimethyl (ADMA) modified peptide GERELEAKARP from the Ubiquitine-like protein 4B. The neutral loss es specific for asymmetrical dimethylation (DMA) are pointed in yellow in the spectra. 


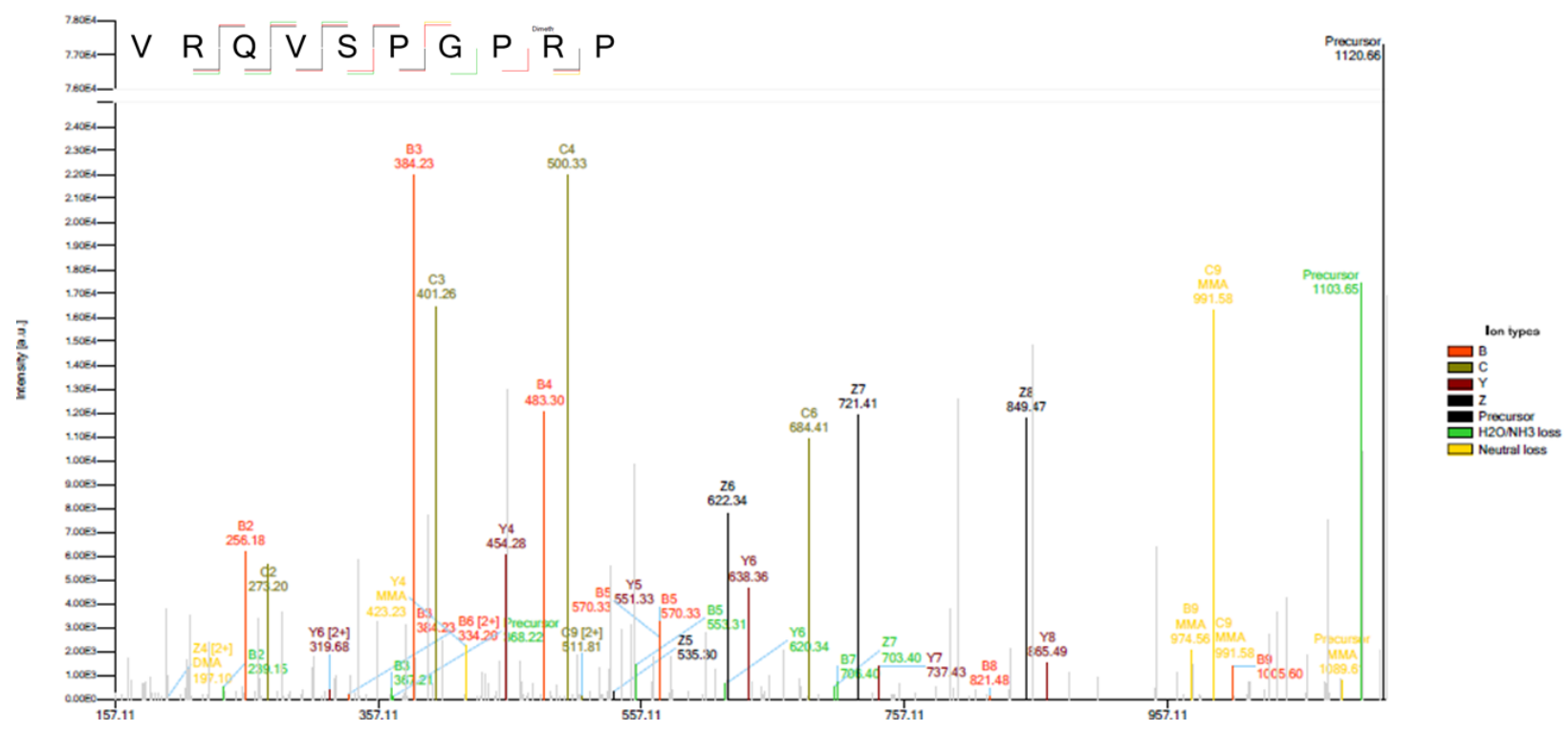

Supplementary Figure 47. EThcD spectra of the P9 symmetrycally dimethyl (SDMA) modified peptide VRQVSPGRP from the Peroxisome proliferator-activated receptor gamma coactivator-related protein 1 . The neutral losses specific for symmetrical dimethylation (MMA) are pointed in yellow in the spectra.

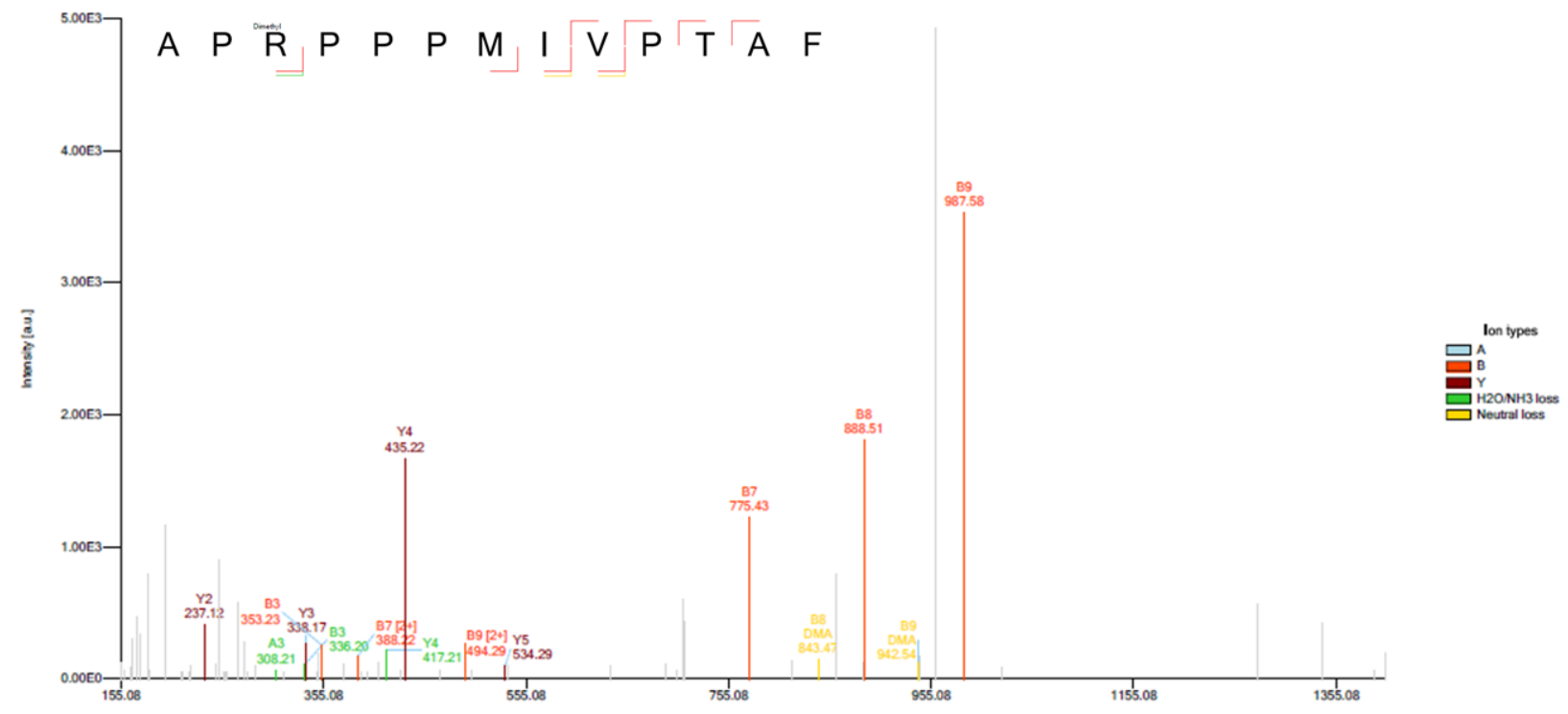


Supplementary Figure 48. HCD spectra of the P3 asymmetrycally dimethyl (ADMA) modified peptide APRPPPPMIVPTAF from the Splicing factor 3A subunit 1 . The neutral losses specific for asymmetrical dimethylation (DMA) are pointed in yellow in the spectra. The peptide was predicted as a HLA-B*07 binder. 